\title{
DIAGNOSE DE FALHAS EM SISTEMAS A EVENTOS DISCRETOS MODELADOS POR AUTÔMATOS FINITOS
}

\author{
João Carlos Basilio* \\ basilio@dee.ufrj.br
}

\author{
Lilian Kawakami Carvalho* \\ lilianecoep.ufrj.br
}

\author{
Marcos Vicente Moreira* \\ moreira@dee.ufrj.br \\ *Universidade Federal do Rio de Janeiro \\ COPPE - Programa de Engenharia Elétrica \\ Cidade Universitária, Ilha do Fundão, Centro de Tecnologia \\ 21949-900, Rio de Janeiro, R.J., Brasil
}

\begin{abstract}
Fault diagnosis of discrete event systems modeled as automata

This tutorial presents the background necessary to the study and research on fault diagnosis of discrete-event systems modeled as automata. Both centralized diagnosability and co-diagnosability with coordination are considered. Besides presenting necessary and sufficient conditions for the verification of diagnosability and co-diagnosability, the paper also presents tests using diagnosers and verifiers. Recent results on centralized diagnosis under partial observation are also addressed.
\end{abstract}

KEYWORDS: Fault diagnosis, Discrete Event Systems, Automata.

\section{RESUMO}

Este tutorial apresenta os fundamentos necessários para o estudo e a pesquisa em diagnose de falhas de sistemas a eventos discretos modelados por autômatos. Tanto a diagnose centralizada quanto a descentralizada com coordenação (codiagnose) são consideradas. Além de apresentar as condições necessárias e suficientes para a verificação da diagnosticabi-

Artigo submetido em 09/10/2009 (Id.: 01046)

Revisado em 30/11/2009, 13/05/2010, 20/05/2010

Aceito sob recomendação da Editora Associada Profa. Emilia Villani lidade e codiagnosticabilidade, este artigo também apresentada testes utilizando diagnosticadores e verificadores. Resultados recentes envolvendo a diagnose centralizada em sistemas sob observação parcial são também considerados.

PALAVRAS-CHAVE: Diagnose de falhas, Sistemas a Eventos Discretos, Autômatos.

\section{INTRODUÇÃO}

A diagnose de falhas em sistemas a eventos discretos (SEDs) tem despertado grande interesse nos últimos anos. As metodologias desenvolvidas para a diagnose de falhas de SEDs podem ser aplicadas não só a sistemas em que o modelo por eventos discretos é o mais apropriado (redes de comunicação e sistemas de computação e de manufatura), como também a diversos sistemas dinâmicos de variáveis contínuas (SDVC), uma vez que esses sistemas podem também ser modelados como SEDs dependendo do grau de abstração.

Dois paradigmas norteiam a diagnose de falhas em SEDs:

1. As falhas a serem diagnosticadas são eventos não observáveis, isto é, eventos cujas ocorrências não podem ser registradas por sensores;

2. A ocorrência de falhas altera o comportamento do sistema, porém não necessariamente leva o sistema a uma parada; por exemplo, em sistemas de manufatura, a ocorrência de uma 
falha não diagnosticada pode levar a uma degradação dos indicadores de eficácia global dos equipamentos (disponibilidade, eficiência e qualidade).

De uma maneira informal, diz-se que um evento de falha pode ser diagnosticado se a sua ocorrência puder ser detectada após a ocorrência de um número finito de eventos observáveis. Para esse fim, são construídos sistemas para a diagnose de falhas, cujo objetivo é inferir e informar a ocorrência de falhas tendo como base somente os eventos que tenham sido observados, isto é, registrados pelos sensores. O projeto desses sistemas requer, em primeiro lugar, a construção de um modelo a eventos discretos do sistema que capture tanto o comportamento normal quanto o comportamento do sistema levando-se em consideração a ocorrência da falha. A segunda parte do projeto é calcada em um arcabouço teórico desenvolvido nas duas últimas décadas e que será revisto neste tutorial e consiste no desenvolvimento de um conjunto de regras (protocolo) a serem seguidas para a identificação e a diagnose de falhas.

Neste tutorial, somente SEDs modelados por autômatos serão considerados (Cassandras e Lafortune, 2008; Hopccroft et al., 2007). O objetivo principal é apresentar os fundamentos necessários para o estudo e a pesquisa em diagnose de falhas considerando tanto a diagnose centralizada quanto a descentralizada com coordenação (codiagnose). Nesse contexto, será apresentada uma breve revisão bibliográfica, cujo objetivo é apenas dar uma idéia geral dos principais tópicos de pesquisa já considerados.

O problema da diagnose de falhas foi trazido para o contexto de SEDs por Lin (1994), que introduziu o conceito da capacidade de se diagnosticar a ocorrência de uma falha em um sistema. Logo a seguir, Sampath et al. (1995) apresentaram condições necessárias e suficientes para a diagnose de falhas de SEDs e propuseram a construção de um autômato diagnosticador que permite tanto inferir sobre a capacidade de diagnosticar as falhas presentes no sistema quanto ser usado para realizar a diagnose de falhas em tempo real. Em um trabalho correlacionado, Sampath et al. (1996) consideraram o problema do desenvolvimento de modelos a eventos discretos para a diagnose de falhas.

Para tornar possível a diagnose de uma falha em SEDs cujos modelos não satisfazem as condições para diagnosticabilidade apresentadas em Sampath et al. (1995), as seguintes soluções podem ser adotadas:

1. Introdução de mais sensores no sistema. Essa abordagem tem a desvantagem de introduzir outros sensores além daqueles realmente necessários para a operação normal do sistema. É, em geral, rejeitada por razões econômicas.

2. Introdução dos chamados sensores virtuais (Sampath,
2001). Sensores virtuais são usados para aumentar a quantidade de informações fornecidas pelos sensores reais do sistema. Essas informações são derivadas por meios analíticos.

3. Uso de ações de controle para alterar a propriedade de diagnosticabilidade de um sistema (Sampath et al., 1998), restringindo-se o comportamento de um sistema nãodiagnosticável através de ações de controle apropriadas para torná-lo diagnosticável. Essa abordagem, diferentemente das soluções 1 e 2 acima, que tratam a diagnose de falhas como passiva, combina observação e controle, sendo esse último problema formulado e resolvido utilizando a teoria de controle supervisório (Ramadge e Wonham, 1989).

Inspirado nos resultados de Lin e Wonham (1990) para controle supervisório descentralizado, Debouk et al. (2000) propuseram uma arquitetura descentralizada com coordenação, denominada codiagnose, que consiste de módulos locais capazes de observar a ocorrência de parte dos eventos observáveis do sistema. Esses módulos locais se comunicam com um coordenador, que é responsável pela diagnose das falhas que venham a ocorrer no sistema. A noção de diagnosticabilidade introduzida por Sampath et al. (1995) foi estendida em Debouk et al. (2000) levando ao conceito de diagnose descentralizada. Em um trabalho posterior, Contant et al. (2006) introduziram o conceito de diagnosticabilidade modular em sistemas que podem ser modelados pela composição paralela de autômatos, em que cada autômato representa um componente local (ou subsistema, ou módulo) do sistema global. Foi mostrado que se o sistema for modularmente diagnosticável, isto é, se cada subsistema for diagnosticável, então a diagnose de falha do sistema global será obtida utilizandose somente os diagnosticadores locais (i.e., os diagnosticadores projetados para cada um dos subsistemas). Mais recentemente, Basilio e Lafortune (2009) apresentaram o conceito de codiagnose robusta, segundo a qual, uma arquitetura descentralizada diagnosticável será robusta se e somente se continuar diagnosticável mesmo com a perda de comunicação entre um ou mais módulos e o coordenador. Condições necessárias e suficientes para codiagnose robusta foram apresentadas em Basilio e Lafortune (2009).

O problema da diagnose de falhas em SEDs estocásticos foi primeiramente considerado por Lunze e Schroder (2001), tendo sido resolvido a partir da formulação de um problema de observação de estados de autômatos estocásticos. Um autômato estocástico é um autômato ao qual é adicionada uma estrutura probabilística para estimar a probabilidade de ocorrência de eventos específicos. Seguindo a mesma linha de Sampath et al. (1995), Thorsley e Teneketzis (2005) apresentaram duas noções de diagnosticabilidade que incorporam a estrutura estocástica do autômato e determinam condições necessárias e suficientes para diagnosticabilidade. A diferença principal entre os trabalhos de Sampath et al. (1995) 
e Thorsley e Teneketzis (2005) é que no primeiro o modelo do SED não pode distinguir entre sequências ou estados que têm elevada probabilidade de ocorrer e aqueles que têm reduzidas chances de ocorrer, enquanto que no último, tais comportamentos improváveis são descartados. Posteriormente, Liu et al. (2008) generalizaram os resultados de Thorsley e Teneketzis (2005) para diagnose descentralizada em SEDs estocásticos utilizando vários diagnosticadores locais baseados no modelo completo do sistema estocástico. De acordo com Liu et al. (2008), um SED estocástico será codiagnosticável se, após a ocorrência de uma falha, existir pelo menos um módulo local tal que a probabilidade desse módulo não diagnosticá-la seja suficientemente pequena.

Outra forma de descrever a incerteza de SEDs é através do autômato fuzzy (Lin e Ying, 2002; Belohlavek, 2002; Li et al., 2006). Para tanto, a definição de autômato de estados finitos é reformulada para permitir a incorporação dos conceitos de lógica fuzzy e conjuntos fuzzy. A diagnosticabilidade de SEDs foi generalizada para o caso de SED fuzzy por Kilic (2008) que propôs o conceito de grau de diagnosticabilidade fuzzy. De acordo com Kilic (2008), se o grau de diagnosticabilidade do sistema for igual a 1, então as ocorrências de todas as falhas do sistema poderão ser diagnosticadas. Caso o grau de diagnosticabilidade seja entre zero e 1, não é possível precisar o tipo da falha que tenha ocorrido. Se o grau de diagnosticabilidade for igual a zero, a linguagem não é diagnosticável.

A inclusão da informação de tempo em SEDs levou aos chamados autômatos temporizados. Nos modelos temporizados, as trajetórias não são especificadas somente em termos de sequências de estados ou eventos, mas devem incluir alguma informação do tempo de ocorrência. Alur e Dill (1994) propuseram o chamado autômato temporizado com guarda que emprega uma forma generalizada para o mecanismo de temporização no qual um conjunto de clocks com dinâmicas dirigidas pelo tempo são incorporados aos autômatos e cujas transições possuem pré-condições estabelecidas em termos dos valores dos relógios, denominadas guardas. Tripakis (2002) estendeu os resultados de Sampath et al. (1995) para SEDs modelados pelos autômatos temporizados com guarda de Alur e Dill (1994), sendo a diagnose de falhas baseada não somente nas sequências de eventos observáveis, mas também nos intervalos de tempo decorridos entre dois eventos sucessivos. Outras abordagens para o problema da diagnose de falhas em SEDs temporizados foram apresentadas por Chen e Provan (1997), Zad et al. (1999) e Zad et al. (2005) que consideraram a diagnose de falhas em modelos a tempo-discreto. Nestes trabalhos, o tempo decorrido entre eventos é modelado tendo como base um evento observável especial denominado "clock tick", sendo o problema da diagnose de falha resolvido utilizando-se técnicas de modelos não-temporizados. Além dessas abordagens, é impor- tante mencionar o trabalho de Holloway e Chand (1996), que propôs uma nova técnica para diagnose de falha distribuída denominada monitoração de padrões, que utiliza conjuntos de temporizações e relações sequenciais para determinar quando estão previstas as ocorrências dos eventos e para precisar se um evento ocorreu ou não.

O conceito de diagnosticabilidade segura foi introduzido por Paoli e Lafortune (2005) segundo o qual, um sistema é dito ter a propriedade da diagnosticabilidade segura se ele for diagnosticável e a detecção de uma falha for realizada antes da execução de um dado conjunto de sequências proibidas após a ocorrência da falha. Recentemente, Qiu et al. (2009) estendeu a propriedade de diagnosticabilidade segura de Paoli e Lafortune (2005) para o caso descentralizado, denominandoa codiagnosticabilidade segura. Nesse caso, quando o sistema executar uma sequência que contenha o evento de falha, deve existir pelo menos um diagnosticador local que possa detectá-la com atraso limitado e antes que viole uma dada especificação de segurança.

Um outro problema frequente em todas as áreas da engenharia é a falha intermitente. Esse tipo de falha pode ocorrer devido a ligações elétricas ruins, componentes que emperram temporariamente, superaquecimento de circuitos integrados, ruído de medição em sensores, entre outros. As metodologias para diagnose de falhas mencionadas nos parágrafos anteriores não são apropriadas para o tratamento de falhas intermitentes pois supõem que, uma vez que a falha tenha ocorrido, o sistema não é capaz de se recuperar da falha; daí a terminologia falhas permanentes. Em um trabalho preliminar, Jiang et al. (2003) consideraram um problema correlato, i.e., a diagnose de falhas repetidas em SEDs, estendendo os resultados de Jiang et al. (2001) e apresentando algumas definições de diagnosticabilidade de falhas repetidas. O problema da diagnose de falhas intermitentes foi, de fato, considerado pela primeira vez por Contant et al. (2004), que propuseram uma extensão do diagnosticador de Sampath et al. (1995) para incorporar as falhas intermitentes. As principais diferenças entre o diagnosticador proposto por Sampath et al. (1995) e o estendido são a introdução de eventos "reset" associados às falhas e de novos rótulos associados aos estados para indicar as seguintes situações: (i) se não houve ocorrência de falha; (ii) se a falha ocorreu e não houve recuperação da falha; (iii) se a falha ocorreu e houve a recuperação da falha. Além disso, condições necessárias e suficientes para a diagnose dessas falhas são apresentadas considerando novos tipos de ciclos indeterminados.

O diagnosticador proposto por Sampath et al. (1995), embora intuitivo e com aplicabilidade na diagnose em tempo real de SEDs, pode ter a sua utilização na verificação da diagnosticabilidade de SEDs comprometida tendo em vista que o espaço de estados do diagnosticador tem complexidade exponencial 
em relação à cardinalidade do espaço de estados do autômato cuja linguagem gerada se deseja diagnosticar. Para contornar esse problema, Jiang et al. (2001) e Yoo e Lafortune (2002) propuseram um novo método para verificar a diagnosticabilidade de SEDs baseado na construção de autômatos não determinísticos denominados verificadores, cujo número de estados cresce de forma polinomial. Mais recentemente, Qiu e Kumar (2006) e Wang et al. (2007) estenderam esses verificadores para a codiagnose, levando aos chamados verificadores descentralizados.

Um outro formalismo para a modelagem de SEDs são as redes de Petri (Peterson, 1981; Murata, 1989; David e Alla, 2005). Recentemente, o problema da diagnose de falhas em sistemas modelados por redes de Petri tem recebido grande atenção (Ushio et al., 1998; Chung et al., 2003; Benveniste et al., 2003; Ramirez-Trevino et al., 2004; Giua e Seatzu, 2005; Genc e Lafortune, 2007; Lefebvre e Delherm, 2007; Manyari-Rivera et al., 2007; Ru e Hadjicostis, 2009; Basile et al., 2009; Dotoli et al., 2009). Contudo, um dos principais problemas ao se considerar modelos em redes de Petri no contexto de diagnose de falhas é que, conforme mostrado por Gaubert e Giua (1999), uma rede de Petri não determinística não pode ser convertida em uma determinística equivalente. Por essa razão, os diagnosticadores obtidos para SEDs modelados por redes de Petri são ainda autômatos. Mais recentemente, Cabasino et al. (2009) apresenta condições necessárias e suficientes para a diagnosticabilidade de redes de Petri rotuladas ilimitadas e propõe um teste para verificar a sua diagnosticabilidade baseado na análise do grafo de cobertura de uma rede de Petri obtida a partir da rede de Petri do sistema inicial.

Este artigo está estruturado da seguinte forma. A seção 2 apresenta uma breve revisão da teoria de SEDs. Na seção 3 é formulado o problema da diagnose de falhas e na seção 4 são apresentadas as condições (necessárias e suficientes) para a diagnose centralizada, e em seguida, é considerado o problema de se diagnosticar uma falha utilizando como conjunto de eventos um subconjunto do conjunto de eventos observáveis original. Ainda na seção 4, é abordado o problema da diagnose descentralizada com coordenação. Na seção 5 consideram-se as condições necessárias e suficientes para a diagnose centralizada e descentralizada utilizando verificadores. Comentários finais e sugestões de tópicos para pesquisa futura são apresentados na seção 6.

\section{SISTEMAS A EVENTOS DISCRETOS}

Sistemas a eventos discretos (SEDs) são sistemas dinâmicos de estados discretos cuja transição de estados se dá através da ocorrência, em geral assíncrona, de eventos. O fato do estado do sistema ser discreto implica que ele pode assumir valores simbólicos, como por exemplo \{ligado, desligado\},
$\{$ verde, amarelo, vermelho\}, ou valores discretos tais como valores numéricos pertencentes aos conjuntos $\mathbb{N}$ ou $\mathbb{Z}$, ou ser formado por um subconjunto enumerável de elementos de $\mathbb{R}$. Eventos podem estar associados a ações específicas (por exemplo, alguém aperta um botão, um avião levanta vôo etc) ou ser o resultado de diversas condições que são satisfeitas (uma peça atinge um determinado ponto de uma linha de produção, o líquido dentro de um tanque atinge uma determinada altura etc). Embora seja possível modelar qualquer sistema físico como um SED de acordo com o grau de abstração considerado, determinados sistemas são naturalmente discretos e com evolução determinada pela ocorrência de eventos.

Assim como na modelagem de sistemas dinâmicos de variáveis contínuas (SDVC), um modelo para um SED deve ser capaz de reproduzir, dentro de limites de tolerância préestabelecidos, o comportamento do sistema. Enquanto nos SDVCs as trajetórias dos estados são descritas em função do tempo, nos SEDs elas são função de uma sequência de eventos. Todas as sequências de eventos possíveis de serem geradas por um SED caracterizam a linguagem desse SED, sendo esta definida sobre o conjunto de eventos (alfabeto) do sistema. Assim, ao se considerar a evolução dos estados de um SED, a maior preocupação é com a sequência de estados visitados e com os eventos que causaram as correspondentes transições de estado, isto é, o modelo de um SED é composto basicamente de dois elementos, estados e eventos, conforme será ilustrado no exemplo a seguir.

Exemplo 1 Considere uma célula de manufatura formada por duas máquinas $\left(M_{1}\right.$ e $\left.M_{2}\right)$ e um robô que transporta as peças de $M_{1}$ para $M_{2}$. A máquina $M_{1}$ recebe peças brutas e quando as peças estão prontas são recolhidas pelo robô. Caso o robô esteja ocupado, a máquina $M_{1}$ retém a peça até que o robô esteja completamente livre. Caso uma outra peça chegue enquanto a máquina $M_{1}$ estiver processando/retendo alguma peça, a máquina $M_{1}$ rejeita a peça recebida. Quando o robô recebe uma peça de $M_{1}$, inicia o transporte desta até a máquina $M_{2}$. No momento em que chegar a $M_{2}$, o robô somente entregará a peça à máquina $M_{2}$ se esta estiver livre; caso contrário reterá a peça até $M_{2}$ ficar disponível. Após entregar a peça a $M_{2}$, o robô retorna à máquina $M_{1}$. A máquina $M_{2}$ recebe a peça do robô e a processa.

A tabela 1 descreve os estados e os eventos das máquinas $M_{1}$ e $M_{2}$ e do robô. Note que os eventos $e_{1}$ (entrega de peça ao robô) e $a_{2}$ (entrega/chegada de peça em $M_{2}$ ) pertencem a dois subsistemas: máquina $M_{1}$ e robô, e robô e máquina $M_{2}$, respectivamente. É importante notar que, para que o evento $e_{1}$ ocorra, a máquina $M_{1}$ deverá estar no estado $H_{1}$ e o robô no estado $I$; para que o evento $a_{2}$ ocorra, o robô deverá estar no estado $H$ e a máquina $M_{2}$ deverá estar no estado $I_{2}$. Para os demais estados do sistema, isto é, aqueles que estão presentes em somente um dos subsistemas, a 
Tabela 1: Os estados e os eventos das máquinas $M_{1}, M_{2}$ e do robô.

\begin{tabular}{ccc}
\hline \hline Elemento & Estados & Eventos \\
\hline \hline & $M_{1}$ disponível: $I_{1}$ & Chegada de peça a $M_{1}: a_{1}$ \\
Máquina $M_{1}$ & $M_{1}$ processando: $P_{1}$ & Fim de processamento: $t_{1}$ \\
& $M_{1}$ retendo peça pronta: $H_{1}$ & Entrega de peça ao robô: $e_{1}$ \\
& $X_{1}=\left\{I_{1}, P_{1}, H_{1}\right\}$ & $E_{1}=\left\{a_{1}, t_{1}, e_{1}\right\}$ \\
\hline & Robô disponível: $I$, & Entrega de peça ao robô: $e_{1}$ \\
Robô & Transportando $M_{1}-M_{2}: T_{12}$ & Chegada a $M_{2}: c_{2}$ \\
& Esperando em $M_{2}: H$ & Entrega/chegada de peça a $M_{2}: a_{2}$ \\
& Retornando para $M_{1}: R$ & Chegada a $M_{1}: r_{1}$ \\
& $X_{r}=\left\{I, T_{12}, H, R\right\}$ & $E_{r}=\left\{e_{1}, c_{2}, a_{2}, r_{1}\right\}$ \\
\hline \multirow{3}{*}{ Máquina $M_{2}$} & $M_{2}$ disponível: $I_{2}$ & Entrega/chegada de peça em $M_{2}: a_{2}$ \\
& $M_{2}$ processando: $P_{2}$ & Fim de processamento: $t_{2}$ \\
& $X_{2}=\left\{I_{2}, P_{2}\right\}$ & $E_{2}=\left\{a_{2}, t_{2}\right\}$ \\
\hline \hline
\end{tabular}

ocorrência não dependerá do estado em que os demais subsistemas estiverem, sendo determinada somente pelo estado atual do subsistema; por exemplo, a ocorrência do evento $t_{1}$ (fim de processamento da peça em $M_{1}$ ) dependerá apenas da máquina $M_{1}$ estar no estado $P_{1}$, independentemente de quais estados estiverem o robô e a máquina $M_{2}$.

\subsection{Linguagem}

Uma linguagem definida sobre um conjunto de eventos $\Sigma$ é um conjunto de sequências (também referidas como cadeias) de comprimentos finitos formadas com os eventos de $\Sigma$. Por exemplo, seja $\Sigma=\{a, b, c, g\}$ um conjunto de eventos. Os seguintes conjuntos são exemplos de linguagens definidas sobre $\Sigma: L_{1}=\{a a, b b, c g\}$ e $L_{2}=\{$ todas as possíveis sequências de eventos de $\Sigma$ terminadas com o evento a $\}$. Note que, enquanto $L_{1}$ tem apenas três elementos, $L_{2}$ é infinita (porém enumerável).

Note que uma linguagem é um subconjunto do conjunto de todas as possíveis sequências de comprimentos finitos formadas com os elementos de $\Sigma$. A esse conjunto dá-se o nome de fecho de Kleene de $\Sigma$, que é denotado por $\Sigma^{*}$. Formalmente, o fecho de Kleene é definido como:

$$
\Sigma^{*}=\{\epsilon\} \cup \Sigma \cup \Sigma \Sigma \cup \Sigma \Sigma \Sigma \cup \ldots,
$$

em que $\epsilon$ denota a sequência vazia e $\Sigma_{a} \Sigma_{b}$ denota a operação de concatenação entre os conjuntos $\Sigma_{a}$ e $\Sigma_{b}$, definida da seguinte forma:

$$
\Sigma_{a} \Sigma_{b}=\left\{\sigma=\sigma_{a} \sigma_{b}: \sigma_{a} \in \Sigma_{a} \text { e } \sigma_{b} \in \Sigma_{b}\right\}
$$

É importante salientar que, como linguagens são conjuntos, as operações usuais de união, interseção, complemento e diferença sejam também válidas para linguagens. Além dessas operações usuais, três importantes operações podem ser definidas para linguagens: a concatenação, o fecho de prefixo e a projeção.

A concatenação entre duas linguagens $L_{1}$ e $L_{2}$ é uma linguagem $L=L_{1} L_{2}$ formada concatenando-se todas as sequências de $L_{1}$ com todas as sequências de $L_{2}$, isto é,

$$
L=L_{1} L_{2}=\left\{s=s_{1} s_{2}: s_{1} \in L_{1} \text { e } s_{2} \in L_{2}\right\} .
$$

O fecho de prefixo de uma linguagem $L$ (denotado por $\bar{L}$ ) é o conjunto formado por todos os prefixos dos elementos de $L$. Uma sequência $u$ será um prefixo de $s$ se existir uma sequência $v$ tal que $s=u v$. Assim, se, por exemplo, $L=$ $\{a, a b, b a\}$, então $\bar{L}=\{\epsilon, a, a b, b, b a\}$. Uma linguagem $L$ tal que $L=\bar{L}$ é dita ser prefixo-fechada.

A projeção $P_{o}$ é definida como (Ramadge e Wonham, 1989):

$$
\begin{aligned}
P_{o}: \Sigma^{*} & \rightarrow \Sigma_{o}^{*}, \text { sendo } \Sigma_{o} \subset \Sigma \\
s & \mapsto P_{o}(s),
\end{aligned}
$$

com as seguintes propriedades:

$$
\begin{aligned}
P_{o}(\epsilon) & =\epsilon, \\
P_{o}(\sigma) & =\left\{\begin{array}{l}
\sigma, \text { se } \sigma \in \Sigma_{o}, \\
\epsilon, \text { se } \sigma \in \Sigma \backslash \Sigma_{o},
\end{array}\right. \\
P_{o}(s \sigma) & =P_{o}(s) P_{o}(\sigma), s \in \Sigma^{*}, \sigma \in \Sigma .
\end{aligned}
$$

O operador projeção pode ser estendido para linguagens de forma natural aplicando a projeção (2) a todas as sequências dessa linguagem. Assim, se $L \subset \Sigma^{*}$ então

$$
P_{o}(L)=\left\{t \in \Sigma_{o}^{*}:(\exists s \in L)\left[P_{o}(s)=t\right]\right\} .
$$

De acordo com a definição acima, a projeção consiste em apagar das sequências de $L$ os eventos que não pertencem a $\Sigma_{o}$. Do ponto de vista prático, essa operação representa a linguagem observada de um sistema, isto é, as sequências formada pelos eventos cujas ocorrências são, de alguma forma, 
do conhecimento do observador. Isso pode gerar ambiguidade, isto é, duas sequências distintas da linguagem podem ter a mesma projeção, o que pode levar a dificuldades tanto no controle quanto na diagnose de falhas de SEDs. A projeção inversa $P_{o}^{-1}$ é definida da seguinte forma:

$$
\begin{aligned}
P_{o}^{-1}: \Sigma_{o}^{*} & \rightarrow 2^{\Sigma^{*}} \\
s & \mapsto P_{o}^{-1}(s)=\left\{t \in \Sigma^{*}: P_{o}(t)=s\right\} .
\end{aligned}
$$

A projeção inversa de uma linguagem $M$ restrita à linguagem $L$ é definida como:

$$
P_{o_{L}}^{-1}(M)=\{s \in L:(\exists y \in M)[P(s)=y]\} .
$$

Para ilustrar o conceito de projeção, considere os seguintes conjuntos de eventos: $\Sigma_{o}=\{a, b\}$ e $\Sigma_{u o}=\{c\}$. Seja $P_{o}:\left(\Sigma_{o} \cup \Sigma_{u o}\right)^{*} \rightarrow \Sigma_{o}^{*}$. Então $P_{o}(\{c b a c\})=\{b a\}$ e $P_{o}^{-1}(\{b a\})=\{c\}^{*}\{b\}\{c\}^{*}\{a\}\{c\}^{*}$. Pode-se, portanto, verificar que $P_{o}\left[P_{o}^{-1}(L)\right]=L$, porém $P_{o}^{-1}\left[P_{o}(L)\right] \supseteq L$.

\subsection{Autômatos}

Uma das maneiras de se modelar SEDs é através de autômatos (também chamados máquinas de estados finitos ou geradores). Formalmente, um autômato (determinístico) é uma sêxtupla

$$
G=\left(X, \Sigma, f, \Gamma, x_{0}, X_{m}\right),
$$

em que $X$ denota o espaço de estados, $\Sigma$ o conjunto de eventos, $f: X \times \Sigma \rightarrow X$ a função de transição de estados (possivelmente $\operatorname{parcial}^{1}$ ), $\Gamma$ a função dos eventos ativos, $x_{0}$ o estado inicial do sistema, e $X_{m} \subseteq X$ o conjunto dos estados marcados.

Autômatos são representados graficamente através de diagramas de transição de estados. Nesses diagramas os estados são representados por circunferências e são conectados entre si por arcos identificados (rotulados) com símbolos, que representam os eventos que determinam as transições entre os estados ligados pelo arco. Os estados marcados são identificados por duas circunferências concêntricas e estão, em geral, relacionados ao cumprimento de uma tarefa a ser realizada pelo sistema modelado pelo autômato. O estado inicial é indicado por uma seta apontada a ele, não oriunda de qualquer outro estado.

Exemplo 2 A figura 1 mostra um diagrama de transição de um autômato $G=\left(X, \Sigma, f, \Gamma, x_{0}, X_{m}\right)$ em que $X=$ $\{0,1,2,3\}, \Sigma=\{a, b\}, x_{0}=0$ e $X_{m}=\{2,3\}$. A evolução dinâmica do autômato representado na figura 1 se dá da seguinte forma. Quando ligado, o sistema se encontra no

\footnotetext{
${ }^{1}$ A função de transição $f$ foi historicamente defi nida como total, isto é, defi nida para todo o domínio $X \times \Sigma$. Em SEDs, é usual considerá-la parcialmente defi nida sobre o seu domínio. O leitor interessado pode ter maiores detalhes em (Cassandras e Lafortune, 2008, pp. 60).
}

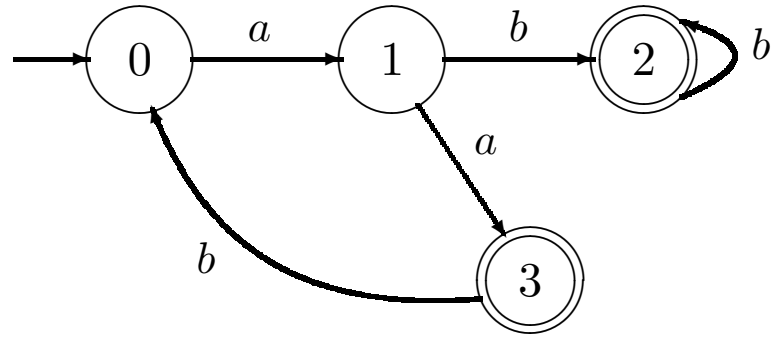

Figura 1: Autômato simples.

estado $x_{0}=0$. Nessa situação, somente o evento $a$ pode ocorrer e, portanto, $\Gamma(0)=\{a\}$. A ocorrência do evento $a$ muda o estado do autômato de 0 para 1 ; formalmente tem-se que $f(0, a)=1$. No estado $x=1$, há duas possibilidades de ocorrência de eventos: $a$ ou $b$, o que é caracterizado pela função dos eventos ativos, isto é, $\Gamma(1)=\{a, b\}$. Se o evento $b$ ocorrer, o estado do sistema mudará para $x=2$ e se $a$ ocorrer, ter-se-á a transição para o estado $x=3$. Note que existe uma transição definida por um autolaço no estado $x=2$, significando que o autômato permanecerá no estado $x=2$, mesmo com a ocorrência do evento $b$.

Um autômato é um dispositivo capaz de representar uma linguagem de acordo com regras bem definidas. São dois os tipos de linguagens que podem ser associadas ao comportamento de um autômato: a linguagem gerada e a linguagem marcada. A linguagem gerada (denotada por $L$ ) representa todos os caminhos que podem ser seguidos no diagrama de transição de estados, começando pelo estado inicial. A linguagem marcada (denotada por $L_{m}$ ) é um subconjunto da linguagem gerada e consiste de todos os caminhos que terminam em um estado marcado no diagrama de transição de estados. Para se definir $L$ e $L_{m}$ formalmente, deve-se inicialmente estender o domínio de $f$ de $X \times \Sigma$ para $X \times \Sigma^{*}$ da seguinte forma recursiva:

$$
\begin{aligned}
f(x, \epsilon) & :=x, \\
f(x, s e) & :=f[f(x, s), e] \text { para } s \in \Sigma^{*} \text { e } e \in \Sigma .
\end{aligned}
$$

Feito isso, pode-se definir $L$ e $L_{m}$ da seguinte forma:

$$
L=\left\{s \in \Sigma^{*}:(\exists x \in X)\left[f\left(x_{0}, s\right)=x\right]\right\}
$$

$\mathrm{e}$

$$
L_{m}=\left\{s \in L: f\left(x_{0}, s\right) \in X_{m}\right\} .
$$

Observe que a linguagem $L$ é prefixo-fechada.

Para o autômato da figura 1 , tem-se que $L=\{\epsilon\} \cup$ $\{a\} \overline{\left[\{a b a\}^{*}\right]}\{b\}^{*}$ e $L_{m}=\{a\}\{a b a\}^{*}\left\{b b^{*}, a\right\}$.

Suponha que $G_{1}=\left(X_{1}, \Sigma_{1}, f_{1}, \Gamma_{1}, x_{0_{1}}, X_{m_{1}}\right)$ e $G_{2}=$ $\left(X_{2}, \Sigma_{2}, f_{2}, \Gamma_{2}, x_{0_{2}}, X_{m_{2}}\right)$ sejam dois autômatos distintos e 
$G_{1}$

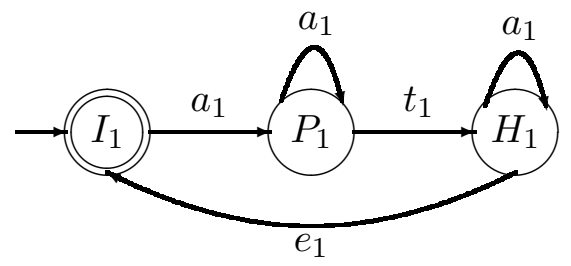

(a)
$G_{r}$

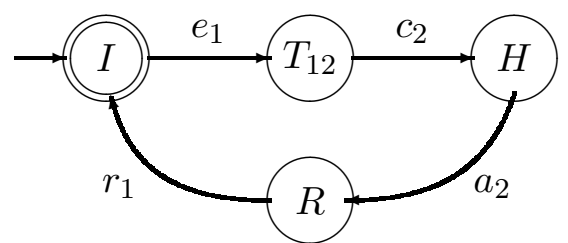

(b)
$G_{2}$

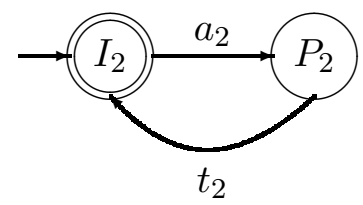

(c)

Figura 2: Máquina $M_{1}$ (a); Robô (b); Máquina $M_{2}$ (c).

que se deseje obter um autômato que modele o comportamento síncrono de $G_{1}$ e $G_{2}$, isto é: (i) um evento comum a $G_{1}$ e $G_{2}$ somente poderá ocorrer quando ambos, $G_{1}$ e $G_{2}$, estiverem em estados cujos conjuntos dos eventos ativos tenham esse evento como elemento; (ii) eventos privados, isto é, pertencentes a $\Sigma_{1} \backslash \Sigma_{2}$ ou a $\Sigma_{2} \backslash \Sigma_{1}$ podem ser executados sempre que possível. Tal autômato existe e pode ser obtido através da chamada composição paralela de $G_{1}$ e $G_{2}$, denotada por $G_{1} \| G_{2}$, e definida da seguinte forma:

$$
\begin{aligned}
G_{1} \| G_{2}= & \operatorname{Ac}\left(X_{1} \times X_{2}, \Sigma_{1} \cup \Sigma_{2}, f_{1 \| 2}, \Gamma_{1 \| 2},\left(x_{0_{1}}, x_{0_{2}}\right),\right. \\
& \left.X_{m_{1}} \times X_{m_{2}}\right),
\end{aligned}
$$

sendo que $\times$ denota o produto cartesiano e Ac denota a parte acessível de $G_{1} \| G_{2}$, a qual é formada pelos estados que podem ser alcançados a partir do estado inicial por uma sequência em $\left(\Sigma_{1} \cup \Sigma_{2}\right)^{*}$. A função de transição de estados de $G_{1} \| G_{2}$ é definida como:

$f_{1 \| 2}\left(\left(x_{1}, x_{2}\right), \sigma\right)=\left\{\begin{array}{l}\left(f_{1}\left(x_{1}, \sigma\right), f_{2}\left(x_{2}, \sigma\right)\right), \text { se } \sigma \in \\ \Gamma_{1}\left(x_{1}\right) \cap \Gamma_{2}\left(x_{2}\right), \\ \left(f_{1}\left(x_{1}, \sigma\right), x_{2}\right), \text { se } \sigma \in \Gamma_{1}\left(x_{1}\right) \backslash \Sigma_{2}, \\ \left(x_{1}, f_{2}\left(x_{2}, \sigma\right)\right), \text { se } \sigma \in \Gamma_{2}\left(x_{2}\right) \backslash \Sigma_{1}, \\ \text { não definido, caso contrário. }\end{array}\right.$

Supondo que $L_{1}=L\left(G_{1}\right)$ e $L_{2}=L\left(G_{2}\right)$, pode-se mostrar que as linguagens gerada e marcada por $G_{1} \| G_{2}$ são dadas por:

$$
\begin{aligned}
L\left(G_{1} \| G_{2}\right) & =P_{1}^{-1}\left(L_{1}\right) \cap P_{2}^{-1}\left(L_{2}\right), \\
L_{m}\left(G_{1} \| G_{2}\right) & =P_{1}^{-1}\left(L_{m_{1}}\right) \cap P_{2}^{-1}\left(L_{m_{2}}\right),
\end{aligned}
$$

sendo $P_{i}:\left(\Sigma_{1} \cup \Sigma_{2}\right)^{\star} \rightarrow \Sigma_{i}^{\star}, i=1,2$.

Outra composição importante entre autômatos é a composição produto. Essa composição permite somente transições com eventos comuns e é definida da seguinte forma:

$$
\begin{aligned}
G_{1} \times G_{2}= & \operatorname{Ac}\left(X_{1} \times X_{2}, \Sigma_{1} \cup \Sigma_{2}, f_{1 \times 2}, \Gamma_{1 \times 2},\right. \\
& \left.\left(x_{0_{1}}, x_{0_{2}}\right), X_{m_{1}} \times X_{m_{2}}\right)
\end{aligned}
$$

sendo

$$
f_{1 \times 2}\left(\left(x_{1}, x_{2}\right), \sigma\right)=\left\{\begin{array}{l}
\left(f_{1}\left(x_{1}, \sigma\right), f_{2}\left(x_{2}, \sigma\right)\right), \text { se } \sigma \in \\
\Gamma_{1}\left(x_{1}\right) \cap \Gamma_{2}\left(x_{2}\right), \\
\text { não definido, caso contrário. }
\end{array}\right.
$$

Se $\Sigma_{1}=\Sigma_{2}$, então a composição paralela reduzir-se-á ao produto, já que todos os eventos são comuns.

Pode-se verificar que as linguagens gerada e marcada de $G_{1} \times G_{2}$ são dadas por:

$$
\begin{aligned}
L\left(G_{1} \times G_{2}\right) & =L_{1} \cap L_{2}, \\
L_{m}\left(G_{1} \times G_{2}\right) & =L_{m_{1}} \cap L_{m_{2}} .
\end{aligned}
$$

Exemplo 3 Para ilustrar o uso da composição paralela, considere a célula de manufatura descrita no exemplo 1 . Com o auxílio da tabela 1, é possível construir os autômatos das máquinas $M_{1}$ e $M_{2}$, e do robô, que serão denotados por $G_{1}$, $G_{2}$ e $G_{r}$, respectivamente. Os correspondentes diagramas de transição estão representados na figura 2.

O modelo do sistema que considera o comportamento síncrono das máquinas $M_{1}, M_{2}$ e do robô será obtido pela composição paralela de $G_{1}, G_{2}$ e $G_{r}$. A figura 3 mostra a composição $G_{r} \| G_{2}$. Note na figura 2 que o evento $a_{2}$ é um evento comum dos autômatos $G_{r}$ e $G_{2}$. Dessa forma, esse evento somente poderá ocorrer quando $G_{r}$ e $G_{2}$ estiverem em estados cujos conjuntos dos eventos ativos tenham, ambos, o evento $a_{2}$ como elemento. Observe que $a_{2}$ não pertence ao conjunto dos eventos ativos do estado $I\left(\right.$ de $G_{r}$ ) e, embora pertença ao conjunto dos eventos ativos de $I_{2}\left(\right.$ de $\left.G_{2}\right)$, não poderá ocorrer quando $G_{r} \| G_{2}$ estiver no estado inicial $\left(I, I_{2}\right)$, conforme mostrado na figura 3 . Esta restrição pode ser entendida mais claramente do ponto de vista prático, pois o robô não poderá entregar uma peça à máquina $M_{2}$ quando estiver parado à espera de peças na máquina $M_{1}$. De fato, conforme mencionado no exemplo 1 , o evento $a_{2}$ somente ocorrerá quando o robô estiver no estado $\mathrm{H}$ e a máquina $M_{2}$ estiver no estado $I_{2}$, como pode ser visto na figura 3 . 


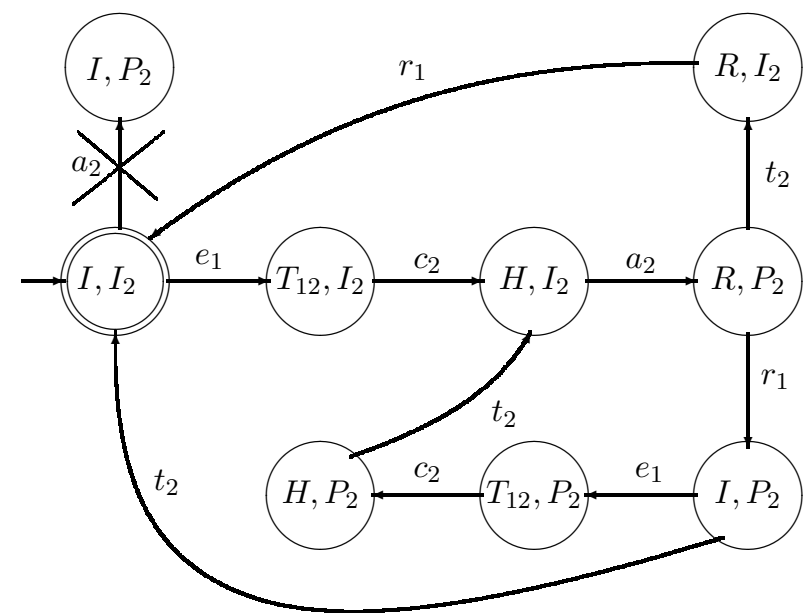

Figura 3: Composição síncrona de $G_{r}$ e $G_{2}$.

Suponha que $\Sigma$ seja particionado como $\Sigma=\Sigma_{o} \dot{U} \Sigma_{u o}$, isto é, $\Sigma=\Sigma_{o} \cup \Sigma_{u o}, \Sigma_{o} \cap \Sigma_{u o}=\emptyset$ e $\Sigma_{u o} \neq \emptyset$, sendo $\Sigma_{o}$ um conjunto de eventos observáveis e $\Sigma_{u o}$ um conjunto de eventos não-observáveis. Um evento é observável quando sua ocorrência puder ser registrada através de sensores ou quando estiver associado a comandos. Os eventos não-observáveis, por sua vez, designam aqueles eventos do sistema cuja ocorrência não pode ser observada por sensores (incluindo os eventos de falhas) ou, embora haja sensores para registrá-los, esses eventos não podem ser vistos em função da natureza distribuída do sistema. Quando $\Sigma=\Sigma_{o} \dot{\cup} \Sigma_{u o}$ tem-se o chamado autômato determinístico com eventos não-observáveis.

O comportamento dinâmico de um autômato determinístico com eventos não-observáveis pode ser descrito por um autômato determinístico, denominado observador, cujo conjunto de eventos é formado pelos eventos observáveis. Os estados do observador são todos os estados em que um autômato determinístico com eventos não-observáveis pode estar após a observação de uma sequência de eventos observáveis. O observador para $G$, denotado por $\operatorname{Obs}(G)$, é definido da seguinte forma:

$$
\operatorname{Obs}(G)=\left(X_{o b s}, \Sigma_{o}, f_{o b s}, \Gamma_{o b s}, x_{0_{o b s}}, X_{m_{o b s}}\right)
$$

sendo $X_{o b s} \in 2^{X}$ e $X_{m_{o b s}}=\left\{B \in X_{o b s}: B \cap X_{m} \neq \emptyset\right\}$. Para a definição de $x_{0_{o b s}}, \Gamma_{o b s}$ e $f_{o b s}$, é necessário introduzir o conceito de alcance não-observável de um estado $x \in X$ (denotado por $U R(x)$ ):

$$
U R(x)=\left\{y \in X:\left(\exists t \in \Sigma_{u o}^{*}\right)[f(x, t)=y]\right\}
$$

De forma análoga, o alcance não-observável de um conjunto $B \in 2^{X}$ é definido como

$$
U R(B)=\bigcup_{x \in B} U R(x)
$$

Usando (8a) e (8b), pode-se definir $x_{0_{o b s}}, \Gamma_{o b s}, f_{o b s}$ e $X_{o b s}$ no algoritmo a seguir.

Algoritmo 1 (Construção de observadores)

Passo 1: Defina $x_{0_{o b s}}=U R\left(x_{0}\right)$ e faça $X_{o b s}=\left\{x_{0_{o b s}}\right\}$ e $\tilde{X}_{o b s}=X_{o b s}$.

Passo 2: $\hat{X}_{o b s}=\tilde{X}_{o b s}$ e $\tilde{X}_{o b s}=\emptyset$.

Passo 3: Para cada $B \in \hat{X}_{o b s}$,

- $\Gamma_{o b s}(B)=\left(\bigcup_{x \in B} \Gamma(x)\right) \cap \Sigma_{o}$;

- Para cada $e \in \Gamma_{\text {obs }}(B)$,

$$
f_{\text {obs }}(B, e)=U R(\{x \in X:(\exists y \in B)[x=f(y, e)]\}) ;
$$

- $\tilde{X}_{o b s} \leftarrow \tilde{X}_{o b s} \cup f_{o b s}(B, e)$.

Passo 4: $X_{o b s} \leftarrow X_{o b s} \cup \tilde{X}_{o b s}$.

Passo 5: Repita os passos 2 a 4 até que toda a parte acessível de $\operatorname{Obs}(G)$ tenha sido construída.

Passo 6: $X_{m_{o b s}}=\left\{B \in X_{o b s}: B \cap X_{m} \neq \emptyset\right\}$.

A idéia do algoritmo 1 é calcular o alcance não-observável para cada estado de $G$ alcançado por um evento observável. Assim, no passo 1 calcula-se o alcance não-observável do estado inicial $x_{0}$ formando o estado inicial do observador. No passo 3 calculam-se os conjuntos dos eventos ativos dos estados do observador obtidos no passo anterior ou na iteração anterior (o primeiro se refere ao alcance observável do estado inicial e o último aos estados de $G$ alcançados por meio de eventos observáveis juntamente com os respectivos alcances não-observáveis). Além disso são calculados os próximos estados do observador, que correspondem aos alcances nãoobserváveis dos estados de $G$ alcançados a partir do estado atual do observador por meio de eventos observáveis. Essa sequência é repetida até que todos os estados acessíveis do observador tenham sido encontrados.

A partir da construção do observador, pode-se concluir que a linguagem gerada por $\operatorname{Obs}(G)$ é a projeção da linguagem de $G$ sobre o conjunto de eventos observáveis, isto é, $L(\operatorname{Obs}(G))=P_{o}[L(G)]$.

Exemplo 4 Para ilustrar a construção de observadores, considere o autômato $G$ da figura 4(a) e suponha que o evento $a$ seja não-observável, isto é, tem-se que $\Sigma=\{a, b, c\}$, $\Sigma_{o}=\{b, c\}$ e $\Sigma_{u o}=\{a\}$. Assim, quando esse autômato inicia sua operação, não é possível precisar se ele ainda está no estado inicial $x_{0}=0$ ou se mudou para o estado $x=1$, uma vez que a ocorrência do evento $a$ não pode ser registrada; daí o estado inicial do observador mostrado na figura 


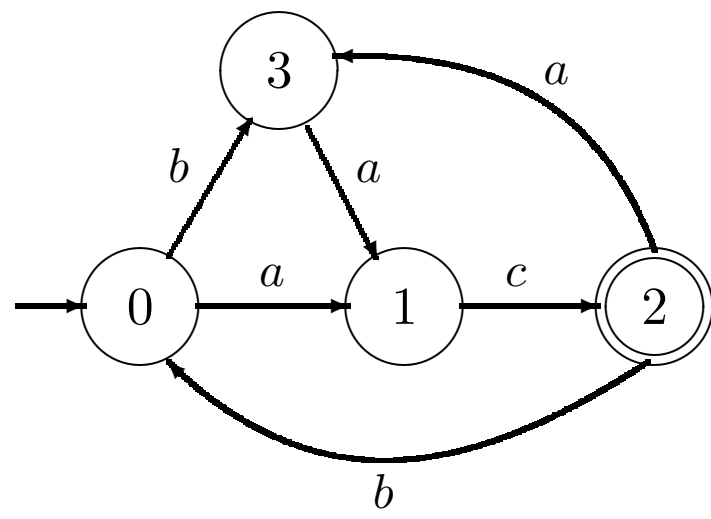

(a)

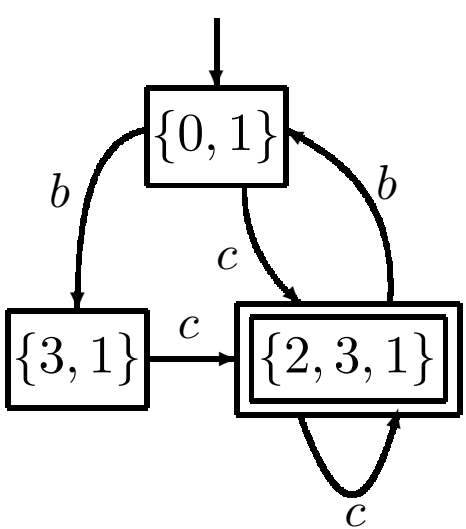

(b)

Figura 4: Um autômato determinístico com eventos não-observáveis (a) e o seu correspondente observador (b).

4(b) ser $\{0,1\}$. Caso o próximo evento observável a ocorrer seja o evento $b$, pode-se, então, afirmar que o autômato estará, inicialmente no estado $x=3$, porém, como o evento $a$ é não-observável, o autômato pode mudar para o estado $x=1$, sem que essa mudança seja percebida; por conseguinte, a transição rotulada pelo evento $b$ no observador leva do estado inicial para o estado $\{3,1\}$. Há ainda transições rotuladas pelo evento $c$ que levam ao estado $\{2,3,1\}$ do observador, partindo tanto do estado inicial quanto do estado $\{3,1\}$, uma vez que o evento $c$ é o único evento observável pertencente aos conjuntos dos eventos ativos dos estados de $G$ que compõem esses dois estados, e os estados $x=3$ e $x=1$ pertencem ao alcance não-observável do estado $x=2$. Finalmente, quando a ocorrência do evento $c$ for registrada, o observador irá permanecer no estado $\{2,3,1\}$. Contudo, se o evento $b$ ocorrer, o observador retornará ao seu estado inicial.

\section{O PROBLEMA DA DIAGNOSE DE FA- LHAS DE SISTEMAS A EVENTOS DIS- CRETOS}

Conforme visto na seção anterior, ao se incorporar eventos não-observáveis no modelo $G$, torna-se possível considerar tanto o comportamento normal do sistema, descrito pelos eventos não-observáveis que não sejam associados a falhas no sistema, como também as falhas que possam ocorrer. Para esse fim, seja $\Sigma_{f} \subseteq \Sigma_{u o}$ o conjunto dos eventos associados às falhas do sistema.

Em geral, o conjunto $\Sigma_{f}$ é particionado em diferentes subconjuntos $\Sigma_{f_{i}}, i=1,2, \ldots, m$, não necessariamente unitários, em que cada conjunto $\Sigma_{f_{i}}$ é formado por eventos que modelam falhas que são, de alguma forma, correlacionadas; o leitor pode obter maiores detalhes sobre esse tópico nos trabalhos de Sampath et al. (1995), Sampath et al.
(1996) e Lafortune et al. (2001). Suponha que $\Pi_{f}=$ $\left\{\Sigma_{f_{1}}, \Sigma_{f_{2}}, \ldots, \Sigma_{f_{m}}\right\}$ denote essa partição. Assim, cada vez que for dito que uma falha $f_{i}$ ocorreu, deve ser entendido que algum evento do conjunto $\Sigma_{f_{i}}$ ocorreu.

Nos trabalhos envolvendo diagnose de falhas em SEDs, as seguintes hipóteses são feitas:

A1. A linguagem gerada por $G$ é viva, i.e., $\Gamma\left(x_{i}\right) \neq \emptyset$ para todo $x_{i} \in X$;

A2. O autômato $G$ não possui nenhum ciclo formado somente por eventos não-observáveis, i.e., $\forall u s t \in L, s \in \Sigma_{u o}^{*}$, $\exists n_{0} \in \mathbb{N}$ tal que $\|s\| \leq n_{0}$, em que $\|s\|$ denota o comprimento da sequência $s$.

A3. Existe somente um único tipo de falha, i.e., $\Pi_{f}=\left\{\Sigma_{f}\right\}$, em que $\Sigma_{f}=\left\{\sigma_{f}\right\}$.

A hipótese A1 é feita tendo em vista que considera-se o sistema em continua operação. A hipótese A2 é necessária para evitar que a ocorrência do evento associado à falha possa vir a não ser detectada caso o sistema fique preso em um ciclo de estados ligados por eventos não observáveis após a sua ocorrência. Essa hipótese será removida ao longo desse tutorial, sendo tais ciclos referidos como escondidos (Basilio e Lafortune, 2009). A hipótese A3 é feita por simplicidade, uma vez que para cada conjunto de eventos de falhas de um mesmo tipo é necessário criar um rótulo diferente; os fundamentos relacionados à análise da diagnosticabilidade são, contudo, os mesmos daqueles empregados para um único tipo de falha.

No estudo de diagnose de falhas de SEDs, as seguintes notações serão utilizadas.

- $s_{f}$ : último evento de uma sequência $s$. 
- $\Psi\left(\Sigma_{f}\right)=\left\{s \in L: s_{f} \in \Sigma_{f}\right\}$ : conjunto de todas as sequências de $L$ que terminam com o evento $\sigma_{f}$.

- $L / s=\left\{t \in \Sigma^{*}:\right.$ st $\left.\in L\right\}:$ continuação da linguagem de $L$ após uma sequência $s$.

Suponha que $\bar{s}$ denote o fecho de prefixo de $s$. Com um ligeiro abuso de notação a relação de pertinência $\Sigma_{f} \in s$ será usada para denotar que $\bar{s} \cap \Psi\left(\Sigma_{f}\right) \neq \emptyset$.

Definição 1 A sequência $s \in L$ é uma sequência que contém uma falha se $\Sigma_{f} \in s$.

A definição acima permite, então, apresentar formalmente a definição de diagnosticabilidade de uma linguagem (Sampath et al., 1995).

Definição 2 Seja $L$ uma linguagem gerada por um autômato $G$ e suponha que $L$ seja viva e prefixo-fechada. Então $L$ é diagnosticavél em relação à projeção $P_{o}$ e $\Sigma_{f}=\left\{\sigma_{f}\right\}$ se a seguinte condição for verificada:

$$
(\exists n \in \mathbb{N})\left(\forall s \in \Psi\left(\Sigma_{f}\right)\right)(\forall t \in L / s)(\|t\| \geq n \Rightarrow D),
$$

sendo a condição de diagnose $D$ expressa por

$$
\left(\forall \omega \in P_{o_{L}}^{-1}\left(P_{o}(s t)\right)\right)\left(\Sigma_{f} \in \omega\right) .
$$

Informalmente, diz-se que a linguagem gerada por um autômato será diagnosticável em relação a um conjunto de eventos observáveis $\Sigma_{o}$ e um conjunto de eventos de falhas $\Sigma_{f}=$ $\left\{\sigma_{f}\right\}$ se a ocorrência de $\sigma_{f}$ puder ser detectada após um número finito de transições depois da ocorrência de $\sigma_{f}$ usando somente sequências de eventos observáveis.

\section{DIAGNOSTICADOR}

Com o objetivo de se realizar a diagnose de falhas a partir da observação do comportamento do sistema em tempo real e para verificar se a linguagem gerada por um autômato $G$ é diagnosticável, pode-se utilizar um autômato determinístico denominado diagnosticador. Além disso, dependendo de como as informações sobre a evolução dinâmica do sistema é disponibilizada, isto é, centralizada em um único sistema de aquisição ou distribuída como no caso de redes de comunicação, sistemas de manufaturas, e sistemas elétricos de potência, podem-se definir duas estruturas para a diagnose de falhas em SEDs:

1. Diagnosticador centralizado: utiliza um único diagnosticador que tem acesso a todos os eventos observáveis do sistema;

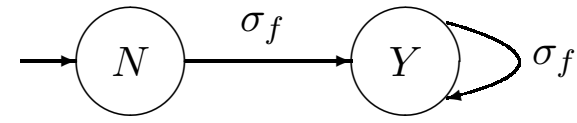

Figura 5: Autômato rotulador.

2. Codiagnosticadores (diagnosticadores descentralizados): a leitura dos sensores não é centralizada, mas sim distribuída em diferentes módulos. Cada módulo observa o comportamento de parte do sistema utilizando um subconjunto do conjunto de eventos observáveis do sistema.

\subsection{Diagnose centralizada}

O diagnosticador centralizado denotado por $G_{d}$ é um autômato cujo conjunto de eventos é igual ao conjunto dos eventos observáveis de $G$ e cujos estados são formados adicionando-se os rótulos $Y$ e $N$ aos estados de $G$ para indicar se o evento $\sigma_{f}$ ocorreu ou não. Formalmente, $G_{d}$ é definido como

$$
G_{d}=\left(X_{d}, \Sigma_{o}, f_{d}, \Gamma_{d}, x_{0_{d}}\right)
$$

e pode ser construído em dois passos: ( $i$ ) obtenha a composição paralela $G \| A_{l}$, sendo $A_{l}$ o autômato rotulador de dois estados mostrados na figura 5; (ii) calcule $\operatorname{Obs}\left(G \| A_{l}\right)$.

É importante observar que o autômato obtido após a composição paralela realizada no passo $(i)$, gera a mesma linguagem que $G$. Além disso, os estados de $G \| A_{l}$ são da forma $(x, Y)$ ou $(x, N)$, dependendo se $\sigma_{f}$ está ou não na sequência que leva $x_{0}$ até $x$; consequentemente $x_{d} \in 2^{X \times\{N, Y\}}$.

Exemplo 5 Para ilustrar a construção de diagnosticadores, considere o autômato cujo diagrama de transição de estados está representado na figura 6(a). As figuras 6(b) e (c) mostram, respectivamente, a composição paralela $G \| A_{l}$ e o diagnosticador $G_{d}=\operatorname{Obs}\left(G \| A_{l}\right)$. Note que o estado 5 de $G$ se divide nos estados $(5, Y)$ e $(5, N)$ de $G \| A_{l}$ devido à existência de duas sequências distintas $\left(s_{1}=\sigma_{f} a b\right.$ e $\left.s_{2}=b a\right)$ que levam $x_{0}=1$ a $x=5$, das quais somente a sequência $s_{1}$ contém o evento de falha $\sigma_{f}$. Para simplificar a notação, é usual representar os estados de $G_{d}$ como $x N$ e $x Y$ ao invés de $(x, Y)$ e $(x, N)$, conforme mostrado na figura 6(c).

Um diagnosticador, tal como aquele representado na figura 6(c) é implementado na prática utilizando-se um computador digital (ou um controlador lógico programável). Seu estado inicial é feito igual a $x_{0_{d}}$, e após qualquer ocorrência de eventos observáveis, seu estado é atualizado de acordo com a função de transição de estados $f_{d}$. Quando o diagnosticador 


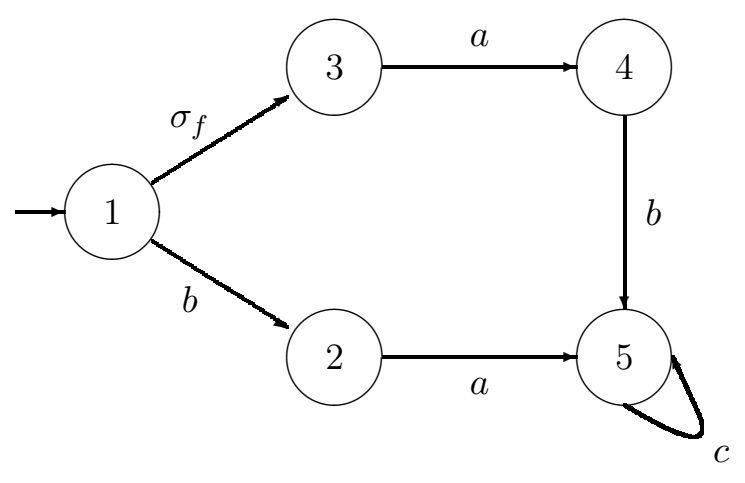

(a)

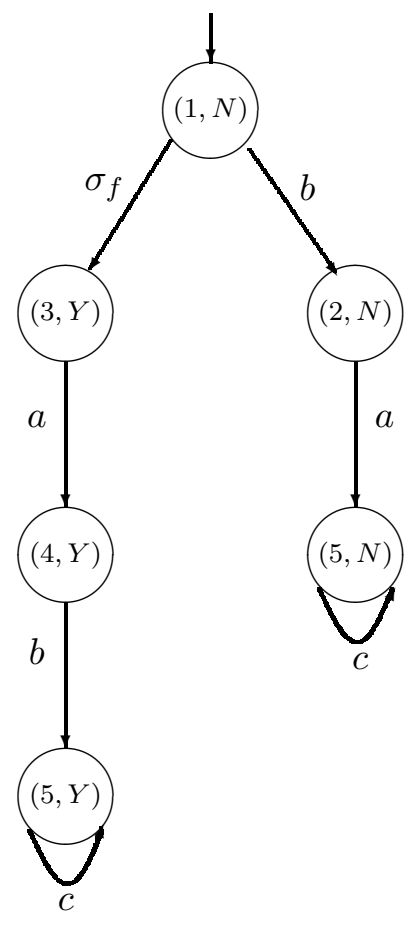

(b)

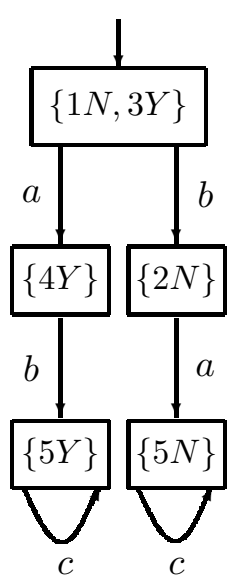

(c)

Figura 6: Autômato $G$ referente ao exemplo 5 (a); composição paralela entre $G$ e $A_{l}$ (b); $G_{d}=O b s\left(G \| A_{l}\right)$ (c).

alcança um estado cujos rótulos são todos iguais a $Y$, ele se torna certo de que a falha ocorreu. Por exemplo, para o autômato da figura 6(a), suponha que tanto o sistema quanto o diagnosticador estejam nos seus respectivos estados iniciais. O estado inicial do diagnosticador $(\{1 N, 3 Y\})$ possui ambos os rótulos $Y$ e $N$, isto é, o evento $\sigma_{f}$, por ser não-observável pode ter ocorrido sem que sua ocorrência seja percebida pelo diagnosticador. Essa possibilidade é levada em consideração pela componente $3 Y$, significando que o sistema pode estar no estado 3 e, nesse caso, com a ocorrência do evento de falha. Por outro lado, como o outro evento que pode ocorrer quando o sistema está no estado inicial é observável, então o diagnosticador deverá indicar que o sistema permaneceu no estado 1 e, por essa razão, a falha não ocorreu; essa possibilidade é representada pela componente $1 N$. Dessa forma, o diagnosticador não poderá afirmar, com certeza, que a falha ocorreu, isto é, ele está incerto com relação à ocorrência ou não do evento associado à falha. Quando o sistema reporta ao diagnosticador a ocorrência do evento $a$, o seu estado muda para $4 Y$, o que torna o diagnosticador certo da ocorrência de $\sigma_{f}$. Por outro lado, se o sistema reporta a ocorrência do evento $b$, o diagnosticador se torna certo da não ocorrência da falha, ou equivalentemente, que o sistema está em uma trajetória normal.

É importante ressaltar que, tendo em vista que $G_{d}=$ $\operatorname{Obs}\left(G \| A_{l}\right)$, então uma vez que o diagnosticador tiver cer- teza da ocorrência da falha, não voltará atrás, isto é, todos os estados seguintes continuarão indicando a falha. Contudo, é possível para um diagnosticador mudar de um estado de não falha para duvidoso ou certo. Nesse contexto, os estados do diagnosticador podem ser classificados, quanto à presença de rótulos $Y$ e $N$, da seguinte forma (Sampath et al., 1995).

Definição 3 Um estado $x_{d} \in X_{d}$ é denominado certo (de falha), se $\ell=Y$ para todo $x \ell \in x_{d}$, e normal (ou de não falha) se $\ell=N$ para todo $x \ell \in x_{d}$. Se existir $x \ell, y \tilde{\ell} \in x_{d}$, $x$ não necessariamente distinto de $y$ tal que $\ell=Y$ e $\tilde{\ell}=N$, então $x_{d}$ é um estado incerto de $G_{d}$.

Usando as definições 2 e 3, é possível estabelecer as seguintes relações entre os estados do diagnosticador e as sequências da linguagem gerada por $G$ (Sampath et al., 1995).

\section{Lema 1}

(i) Seja $x_{d}=f_{d}\left(x_{0_{d}}, s\right)$. Se $x_{d}$ é um estado certo, então para todo $\omega \in P_{o_{L}}^{-1}(s), \Sigma_{f} \in \omega$.

(ii) Se $x_{d}$ é um estado incerto, então existem $s_{1}, s_{2} \in L$ tais que $\Sigma_{f} \in s_{1}$ e $\Sigma_{f} \notin s_{2}$, porém $P_{o}\left(s_{1}\right)=P_{o}\left(s_{2}\right)$ e $f_{d}\left(x_{0_{d}}, P_{o}\left(s_{1}\right)\right)=f_{d}\left(x_{0_{d}}, P_{o}\left(s_{2}\right)\right)=x_{d}$.

Uma consequência imediata da definição 2 e do lema 1 é que a linguagem gerada por $G$ será diagnosticável com relação a 
$\Sigma_{f}$ e $P_{o}$ se, e somente se, o diagnosticador sempre alcançar um estado certo para toda sequência arbitrariamente longa de $L$ que contiver o evento $\sigma_{f}$. Isso não irá ocorrer se, e somente se, existir uma sequência de $L$ que faça o diagnosticador ficar preso indefinidamente em um laço formado por estados incertos. Para explorar mais profundamente esse problema, considere as seguintes definiçõos (Sampath et al., 1995).

Definição 4 Seja $L(G, x)=\left\{s \in \Sigma^{*}: f(x, s) \in X\right\}$, isto é, o conjunto formado por todas as sequências que levam o autômato $G$ do estado $x \in X$ a um outro estado do autômato. Um conjunto de estados $\left\{x_{1}, x_{2}, \ldots, x_{n}\right\} \subset X$ forma um ciclo em um autômato $G$ se existir uma sequência $s=\sigma_{1} \sigma_{2} \ldots \sigma_{n} \in L\left(G, x_{1}\right)$ tal que $f\left(x_{l}, \sigma_{l}\right)=x_{l+1}$, $l=1, \ldots, n-1$, e $f\left(x_{n}, \sigma_{n}\right)=x_{1}$.

Definição 5 Um conjunto de estados incertos $\left\{x_{d_{1}}, x_{d_{2}}, \ldots, x_{d_{p}}\right\} \subset X_{d}$ forma um ciclo indeterminado se as seguintes condições forem satisfeitas:

1) $x_{d_{1}}, x_{d_{2}}, \ldots, x_{d_{p}}$ forma um ciclo em $G_{d}$;

2) $\exists\left(x_{l}^{k_{l}}, Y\right),\left(\tilde{x}_{l}^{r_{l}}, N\right) \in x_{d_{l}}, x_{l}^{k_{l}}$ não necessariamente distinto de $\tilde{x}_{l}^{r_{l}}, l=1,2, \ldots, p, k_{l}=1,2, \ldots, m_{l}$, e $r_{l}=$ $1,2, \ldots, \tilde{m}_{l}$ de tal sorte que as sequências de estados $\left\{x_{l}^{k_{l}}\right\}$, $l=1,2, \ldots, p, k_{l}=1,2, \ldots, m_{l}$ e $\left\{\tilde{x}_{l}^{r_{l}}\right\}, l=1,2, \ldots, p$, $r_{l}=1,2, \ldots, \tilde{m}_{l}$ podem ser rearranjadas para formar ciclos em $G$, cujas sequências correspondentes $s$ e $\tilde{s}$, formadas com os eventos que definem a evolução dos ciclos, têm como projeção $\sigma_{1} \sigma_{2} \ldots \sigma_{p}$, em que $\sigma_{1}, \sigma_{2}, \ldots, \sigma_{p}$ são definidos de acordo com o item 1).

Usando as definições 2, 4 e 5 e o lema 1, pode-se enunciar a seguinte condição necessária e suficiente para a diagnose de uma linguagem.

Teorema 1 Uma linguagem $L$ gerada por um autômato $G$ será diagnosticável com relação à projeção $P_{o}$ e $\Sigma_{f}=\left\{\sigma_{f}\right\}$ se, e somente se, o seu diagnosticador $G_{d}$ não tiver ciclos indeterminados.

\section{Exemplo 6}

1) Considere o autômato da figura 6(a). Note que o diagnosticador de $G$, mostrado na figura 6(c) não possui ciclos indeterminados. Dessa forma, pode-se concluir que $L$ é diagnosticável em relação a $\Sigma_{o}$ e $\Sigma_{f}=\left\{\sigma_{f}\right\}$.

2) Considere, agora, o autômato $G$ cujo diagrama de transição de estados está representado na figura 7(a). Suponha que $\Sigma=\left\{a, b, c, \sigma_{f}\right\}, \Sigma_{o}=\{a, c\}, \Sigma_{u o}=\left\{b, \sigma_{f}\right\} \mathrm{e}$ $\Sigma_{f}=\left\{\sigma_{f}\right\}$. O diagnosticador $G_{d}$ associado a $G$ pode ser visto na figura $7(\mathrm{~b})$. Observe que o estado $\{4 Y, 6 N\}$ é um estado incerto e como $f_{d}(\{4 Y, 6 N\}, c)=\{4 Y, 6 N\}$, então o

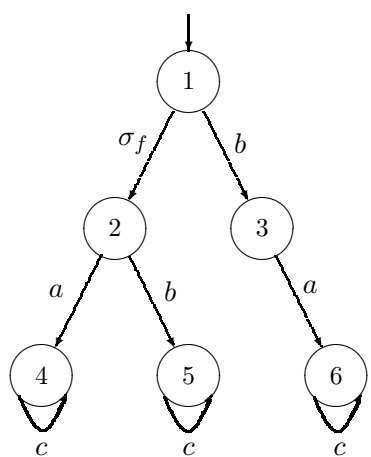

(a)

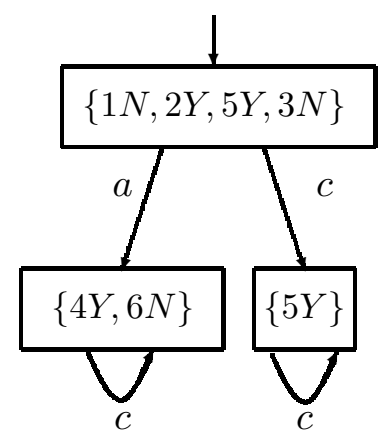

(b)
Figura 7: (a) Autômato $G$; (b) Diagnosticador centralizado para $G$.

estado incerto $\{4 Y, 6 N\}$ forma um ciclo em $G_{d}$. Além disso, associados, respectivamente, às componentes $\{4 Y\}$ e $\{6 N\}$ de $\{4 Y, 6 N\}$, existem em $G$ dois ciclos formados pelos estado 4 e 6 (ver figura 7(a)). Logo, $\{4 Y, 6 N\}$ forma um ciclo indeterminado em $G_{d}$. Pode-se, portanto, concluir que $L$ é não diagnosticável em relação $P_{o}$ e $\Sigma_{f}$.

Observação 1 (i) De acordo com a definição 2, a diagnose da linguagem gerada por $G$ se baseia em um único conjunto de eventos observáveis, ou equivalentemente, na projeção $P_{o}: \Sigma^{*} \rightarrow \Sigma_{o}^{*}$. Isso significa que, na prática, a decisão sobre a ocorrência ou não de uma falha é tomada por um diagnosticador central. Por essa razão, esse problema é usualmente referido na literatura como problema da diagnose centralizada e o autômato $G_{d}$ é chamado diagnosticador centralizado.

(ii) É importante ressaltar que a existência de um ciclo de estados incertos no diagnosticador não necessariamente implica na impossibilidade de se diagnosticar a ocorrência de uma falha. Para que $L$ seja diagnosticável em relação a $P_{o}$ e $\Sigma_{f}$, não pode existir um ciclo de estados em $G$ após a ocorrência da falha que corresponda ao ciclo de estados incertos no diagnosticador. Um exemplo que ilustra essa situação pode ser encontrado em Cassandras e Lafortune (2008, pp.114).

\subsection{Diagnose centralizada sob observa- ção parcial}

O conceito de diagnose de uma linguagem apresentado na definição 2 leva em conta não somente a linguagem gerada por um autômato, mas também o conjunto de eventos observáveis e a partição do conjunto de falhas. A dependência da diagnose da linguagem em relação ao conjunto de eventos observáveis sugere a possibilidade da linguagem gerada por 
um autômato ser também diagnosticada com relação a $\Sigma_{f}$ e à projeção $P_{o^{\prime}}: \Sigma^{*} \rightarrow \Sigma_{o}^{\prime *}$, para algum subconjunto $\Sigma_{o}^{\prime}$ de $\Sigma_{o}$. Para abordar esse problema, além das hipóteses A1-A3, a seguinte hipótese será feita (Basilio e Lafortune, 2009):

A4. $L$ é diagnosticável com relação à projeção $P_{o}: \Sigma^{*} \rightarrow$ $\Sigma_{o}^{*}$ e $\Sigma_{f}$ (diagnose centralizada).

Suponha que $G_{d}^{\prime}=\left(X_{d}^{\prime}, \Sigma_{o}^{\prime}, f_{d}^{\prime}, \Gamma_{d}^{\prime}, x_{0_{d}}^{\prime}\right)$ denote um diagnosticador para $L$ supondo observação parcial, isto é, $G_{d}^{\prime}$ é capaz de observar somente os eventos pertencentes a um conjunto $\Sigma_{o}^{\prime} \subset \Sigma_{o}$. O seguinte resultado pode ser enunciado.

Teorema 2 Suponha que $G_{d}=\left(X_{d}, \Sigma_{o}, f_{d}, \Gamma_{d}, x_{0_{d}}\right)$ e $G_{d}^{\prime}=\left(X_{d}^{\prime}, \Sigma_{o}^{\prime}, f_{d}^{\prime}, \Gamma_{d}^{\prime}, x_{0_{d}}^{\prime}\right)$ denotem diagnosticadores centralizados, supondo observação total e parcial, respectivamente, isto é, $\Sigma_{o}^{\prime} \subset \Sigma_{o}$ e $\Sigma_{o}^{\prime} \neq \emptyset$. Então, $\operatorname{Obs}\left(G_{d}, \Sigma_{o}^{\prime}\right)=$ $\left(\hat{X}_{d}, \Sigma_{o}^{\prime}, \hat{f}_{d}, \hat{\Gamma}_{d}, \hat{x}_{0_{d}}\right)$ (o observador de $G_{d}$ em relação à projeção $\left.P_{o o^{\prime}}: \Sigma_{o}^{*} \rightarrow \Sigma_{o}^{*}\right)$ e $G_{d}^{\prime}$ são idênticos a menos da seguinte relação de equivalência entre os seus estados:

$$
\begin{aligned}
\hat{x}_{d} & =\left\{x_{d_{1}}, x_{d_{2}}, \ldots, x_{d_{n}}\right\} \in \hat{X}_{d}, x_{d_{i}} \in X_{d} \Leftrightarrow \\
x_{d}^{\prime} & =\bigcup_{i=1}^{n} x_{d_{i}} \in X_{d}^{\prime} .
\end{aligned}
$$

Demonstração. Seja $\Sigma=\Sigma_{o} \cup \Sigma_{u o}$, e considere um conjunto não vazio $\Sigma_{o}^{\prime} \subset \Sigma_{o}$. Defina:

(i) $G_{l}=G \| A_{l}=\left(X_{l}, \Sigma, f_{l}, \Gamma_{l}, x_{0_{l}}\right)$;

(ii) $G_{d}=\operatorname{Obs}\left(G_{l}, \Sigma_{o}\right)=\left(X_{d}, \Sigma_{o}, f_{d}, \Gamma_{d}, x_{0_{d}}\right)$;

(iii) $G_{d}^{\prime}=\operatorname{Obs}\left(G_{l}, \Sigma_{o}^{\prime}\right)=\left(X_{d}^{\prime}, \Sigma_{o}^{\prime}, f_{d}^{\prime}, \Gamma_{d}^{\prime}, x_{0_{d}}^{\prime}\right)$;

(iv) $\hat{G}_{d}=\operatorname{Obs}\left(G_{d}, \Sigma_{o}^{\prime}\right)=\left(\hat{X}_{d}, \Sigma_{o}^{\prime}, \hat{f}_{d}, \hat{\Gamma}_{d}, \hat{x}_{0_{d}}\right)$.

Note que as linguagens geradas por $\hat{G}_{d}$ e $G_{d}^{\prime}$ são iguais, isto é, $L\left(\hat{G}_{d}\right)=L\left(G_{d}^{\prime}\right)$, uma vez que $P_{o o^{\prime}}\left[P_{o}(s)\right]=$ $P_{o^{\prime}}(s), \forall s \in L$, sendo $P_{o o^{\prime}}: \Sigma_{o}^{*} \rightarrow \Sigma_{o}^{\prime *}$ e $P_{o^{\prime}}: \Sigma^{*} \rightarrow \Sigma_{o}^{\prime *}$.

Seja $\hat{x}_{d} \in \hat{X}_{d}$ um estado de $\hat{G}_{d}$ alcançável por uma sequência $s^{\prime} \in L\left(\hat{G}_{d}\right)$. Então, para todo $x_{d_{i}} \in \hat{x}_{d}, i \in$ $\{1,2, \ldots, n\}$, existe uma sequência $s_{d_{i}} \in L\left(G_{d}\right)$ tal que $P_{o o^{\prime}}\left(s_{d_{i}}\right)=s^{\prime}$ e $f_{d}\left(x_{0_{d}}, s_{d_{i}}\right)=x_{d_{i}}$. Da mesma forma, para todo $x_{l} \in x_{d_{i}}$ existe uma sequência $s \in L\left(G_{l}\right)$ tal que $P_{o}(s)=s_{d_{i}}$ e $f_{l}\left(x_{0_{l}}, s\right)=x_{l}$. Portanto, como $G_{d}^{\prime}$ é um autômato determinístico e $P_{o o^{\prime}}\left[P_{o}(s)\right]=P_{o^{\prime}}(s)$, então existe $x_{d}^{\prime}=f_{d}^{\prime}\left(x_{0_{d}}^{\prime}, s^{\prime}\right)$ tal que $x_{l} \in x_{d}^{\prime}$. Dessa forma, para todo $x_{l} \in x_{d_{i}} \in \hat{x}_{d}$ tem-se que $x_{l} \in x_{d}^{\prime}$ e, portanto, $\bigcup_{i=1}^{n} x_{d_{i}} \subseteq x_{d}^{\prime}$.

Sejam, agora, $x_{d}^{\prime} \in X_{d}^{\prime}$ e $s^{\prime} \in L\left(G_{d}^{\prime}\right)$ que satisfazem $x_{d}^{\prime}=$ $f_{d}^{\prime}\left(x_{0_{d}}^{\prime}, s^{\prime}\right)$. Logo, existem $s \in L\left(G_{l}\right)$, com $s^{\prime}=P_{o^{\prime}}(s)$, e $x_{l}=f_{l}\left(x_{0_{l}}, s\right)$ tal que $x_{l} \in x_{d}^{\prime}$. Como $\hat{G}_{d}$ é um autômato determinístico e $P_{o o^{\prime}}\left[P_{o}(s)\right]=s^{\prime}$, então existem $x_{d_{i}}=$ $f_{d}\left(x_{0_{d}}, P_{o}(s)\right)$ e $\hat{x}_{d}=\hat{f}_{d}\left(\hat{x}_{0_{d}}, s^{\prime}\right)$ tais que $x_{l} \in x_{d_{i}} \in \hat{x}_{d}$. Consequentemente, $x_{d}^{\prime} \subseteq \bigcup_{i=1}^{n} x_{d_{i}}$.

Observação $2 \mathrm{O}$ diagnosticador $G_{d}^{\prime}$ será referido neste artigo como diagnosticador centralizado com observação parcial, ou simplesmente diagnosticador parcial.

De acordo com o teorema 2, o diagnosticador parcial $G_{d}^{\prime}$ que observa eventos pertencentes ao subconjunto $\Sigma_{o}^{\prime}$ do conjunto dos eventos observáveis $\Sigma_{o}$ pode ser construído diretamente a partir do diagnosticador centralizado $G_{d}$ calculando-se $\operatorname{Obs}\left(G_{d}, \Sigma_{o}^{\prime}\right)$ e substituindo-se cada um dos estados de $\operatorname{Obs}\left(G_{d}, \Sigma_{o}^{\prime}\right)$ pela união dos conjuntos que formam cada um desses estados. Além disso, como $L\left(G_{d}^{\prime}\right)=$ $L\left(O b s\left(G_{d}, \Sigma_{o}^{\prime}\right)\right)=P_{o o^{\prime}}\left(L\left(G_{d}\right)\right)$, sendo $P_{o o^{\prime}}: \Sigma_{o}^{*} \rightarrow \Sigma_{o}^{\prime *}$, então embora a linguagem gerada pelo diagnosticador centralizado com observação total seja por hipótese viva, as linguagens geradas por diagnosticadores parciais não são necessariamente vivas. Isso ocorre sempre que os eventos que formam um ciclo em $G_{d}$ se tornam não-observáveis no diagnosticador parcial; não é dificil verificar que quando isso acontece, esse ciclo se reduz a um único estado em $G_{d}^{\prime}$ (Basilio e Lafortune, 2009). Quando, após o sistema alcançar um determinado estado, ocorrer um ciclo de estados ligados por eventos não-observáveis, não haverá mudança de estado no diagnosticador parcial, embora os estados reais do autômato mudem de forma cíclica. Nesse caso, diz-se que esse diagnosticador parcial possui um ciclo escondido nesse estado.

Definição 6 (Ciclos escondidos e ciclos escondidos indeterminados) Suponha que $x_{d}^{\prime} \in X_{d}^{\prime}$ tenha sido obtido agrupando-se os estados $x_{d_{1}}, x_{d_{2}}, \ldots, x_{d_{n}} \in X_{d}$. Então, existe um ciclo escondido em $x_{d}^{\prime}$ de $G_{d}^{\prime}$ se para al$\operatorname{gum}\left\{i_{1}, i_{2}, \ldots, i_{k}\right\} \subseteq\{1,2, \ldots, n\},\left\{x_{d_{i_{1}}}, x_{d_{i_{2}}}, \ldots, x_{d_{i_{k}}}\right\}$ forma um ciclo em $G_{d}$. Além disso, se $x_{d}^{\prime}$ é um estado incerto e todos os estados $x_{d_{i_{1}}}, x_{d_{i_{2}}}, \ldots, x_{d_{i_{k}}}$ são certos, então o ciclo escondido é denominado indeterminado.

Os ciclos escondidos serão representados nos diagramas de transição de estados dos diagnosticadores parciais por laços tracejados: os ciclos escondidos indeterminados serão rotulados como ihc (do inglês indeterminate hidden cycle) e os ciclos escondidos em estados normais, em estados certos ou em estados incertos cujos ciclos escondidos não sejam formados por estados certos de $G_{d}$ serão rotulados simplesmente como hc. Conforme será visto mais à frente, a existência de ciclos escondidos que não sejam indeterminados não leva à perda de diagnosticabilidade da linguagem quando se tem apenas observação parcial dos eventos.

De acordo com a condição para diagnose dada na definição 2, todas as sequências $s \in \Psi\left(\Sigma_{f}\right)$ devem ser diagnosticadas pelo diagnosticador parcial $G_{d}^{\prime}$. Uma sequência $s \in \Psi\left(\Sigma_{f}\right)$ 


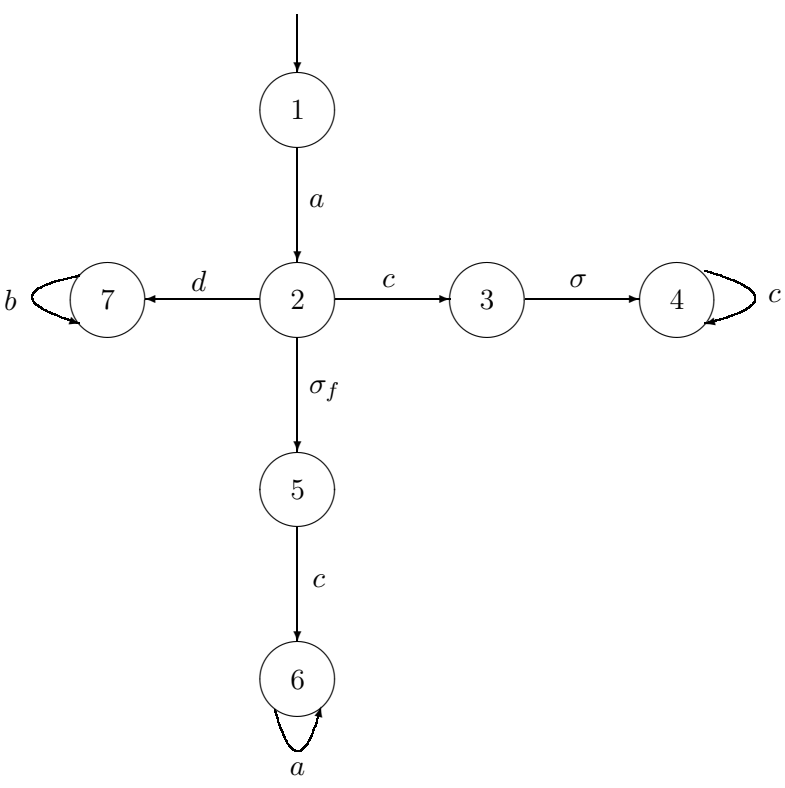

Figura 8: Autômato $G$ cuja ocorrência do evento $\sigma_{f}$ deve ser diagnosticada.

que não pode ser diagnosticada pelo diagnosticador parcial é chamado de sequência ambígua.

Definição 7 (Sequência ambígua) Uma sequência $s \in L$ é uma sequência ambígua em relação à projeção $P_{o^{\prime}}: \Sigma^{*} \rightarrow$ $\Sigma_{o}^{\prime *}$ e $\Sigma_{f}$ se existir uma sequência $s^{\prime} \in L$ tal que $\Sigma_{f} \in s$, porém $\Sigma_{f} \notin s^{\prime}$, e $P_{o^{\prime}}(s)=P_{o^{\prime}}\left(s^{\prime}\right)$.

O teorema a seguir provê uma condição necessária e suficiente para a diagnose de falhas sob observação parcial.

Teorema 3 Suponha que a linguagem $L$ seja diagnosticável em relação à projeção $P_{o}$ e $\Sigma_{f}$. Então $L$ será também diagnosticável em relação à projeção $P_{o^{\prime}}: \Sigma^{*} \rightarrow \Sigma_{o}^{\prime *}, \Sigma_{o}^{\prime} \subset \Sigma_{o}$, e $\Sigma_{f}=\left\{\sigma_{f}\right\}$ se, e somente se, $G_{d}^{\prime}$ não tiver nenhum ciclo indeterminado (incluindo ciclos escondidos).

Exemplo 7 Para ilustrar o resultado do teorema 3, considere o autômato $G=\left(X, \Sigma, f, \Gamma, x_{0}, X_{m}\right)$ cujo diagrama de transição de estados está representado na figura 8. Suponha que $\Sigma=\left\{a, b, c, d, \sigma, \sigma_{f}\right\}, \Sigma_{o}=\{a, b, c, d\}, \Sigma_{u o}=$ $\left\{\sigma, \sigma_{f}\right\}$ e $\Sigma_{f}=\left\{\sigma_{f}\right\}$. O diagnosticador $G_{d}$ associado a $G$ pode ser visto na figura 9(a), de onde se pode notar que $L$ é diagnosticável em relação a $P_{o}$ e $\Sigma_{f}$, uma vez que $G_{d}$ não tem nenhum ciclo indeterminado.

Considere agora o problema de verificar se $L$ é também diagnosticável em relação à projeção $P_{o^{\prime}}: \Sigma^{*} \rightarrow \Sigma_{o}^{\prime *}$ e $\Sigma_{f}$, sendo $\Sigma_{o}^{\prime}=\{c, d\} \subset \Sigma_{o}$. O diagnosticador parcial $G_{d}^{\prime}$ correspondente ao conjunto de eventos observáveis $\Sigma_{o}^{\prime}$ está representado na figura $9(\mathrm{~b})$, de onde se pode ver que $G_{d}^{\prime}$ tem um ciclo escondido indeterminado no estado $\{3 N, 4 N, 6 Y\}$. Como consequência, $L$ é não diagnosticável em relação a $P_{O^{\prime}}$ e $\Sigma_{f}$. A justificativa para a não diagnose de $L$ com relação a $P_{o^{\prime}}$ é a existência da sequência $s=a \sigma_{f} c a^{n}, n \in \mathbb{N}$, que contém o evento de falha $\sigma_{f}$, e que possui a mesma projeção em relação a $P_{o^{\prime}}$ que uma sequência normal $s^{\prime}=a c$, isto é, $P_{o^{\prime}}(s)=P_{o^{\prime}}\left(s^{\prime}\right)=c$; consequentemente $s$ é uma sequência ambígua ( $s$ é, na verdade, a única sequência ambígua nesse exemplo). Para se obter um novo subconjunto de $\Sigma_{o}$ que faça com que $L$ possa ser diagnosticada sob observação parcial, note que $a \in s$, porém $a \notin \Sigma_{o}^{\prime}$. Dessa forma, acrescentando-se o evento $a$ ao conjunto de eventos observáveis $\Sigma_{o}^{\prime}$, e formando um novo conjunto de eventos observáveis $\Sigma_{o}^{\prime \prime}=\{a, c, d\}$, é esperado que $L$ se torne diagnosticável em relação $P_{o^{\prime \prime}}: \Sigma^{*} \rightarrow \Sigma_{o}^{\prime \prime *}$ e $\Sigma_{f}$. Isso, de fato, acontece, uma vez que $G_{d}^{\prime \prime}$ não possui ciclos indeterminados (incluindo ciclos escondidos), conforme pode ser visto na figura 9 (c).

\subsection{Diagnose descentralizada com coor- denadação (codiagnose)}

A fim de se contornar o problema da natureza distribuída de alguns sistemas, foi proposta em Debouk et al. (2000) a estrutura descentralizada mostrada na figura 10. Nessa arquitetura descentralizada, as leituras provenientes dos sensores não são centralizadas e sim distribuídas em diferentes módulos $M_{i}, i=1,2, \ldots, N$, cada um observando o comportamento do sistema tendo como base as informações fornecidas pelos sensores conectados a ele, isto é, a partir de conjuntos de eventos observáveis $\Sigma_{o_{i}}, i=1,2, \ldots, N$. Cada módulo processa a informação recebida (ocorrência de eventos), e, no caso da arquitetura descentralizada proposta por Debouk et al. (2000), somente podem comunicar os seus diagnósticos ao coordenador. A cada instante, cada módulo reporta ao coordenador o seu diagnóstico, e o coordenador processa essa informação de acordo com uma regra pré-estabelecida e toma uma decisão no que diz respeito à ocorrência ou não da falha. É importante observar que o coordenador não tem qualquer conhecimento do modelo do sistema, e tem, em geral, capacidades de memória e processamento limitados.

A diagnose da linguagem $L$ pela estrutura descentralizada com coordenação representada na figura 10 depende, além do conjunto de falhas $\Sigma_{f}$, de outros quatro elementos, quais sejam: (i) as regras usadas para gerar os diagnósticos locais; (ii) as regras de comunicação entre os módulos e o coordenador; (iii) as regras de decisão empregadas pelo coordenador para a diagnose das falhas; (iv) as projeções

$$
P_{o_{i}}: \Sigma^{*} \rightarrow \Sigma_{o_{i}}^{*}, i=1,2, \ldots, N,
$$

associadas a cada módulo $M_{i}$. Ao conjunto dos elementos (i), (ii) e (iii) dá-se o nome de protocolo.

Suponha que $C$ denote a informação passada ao coordena- 


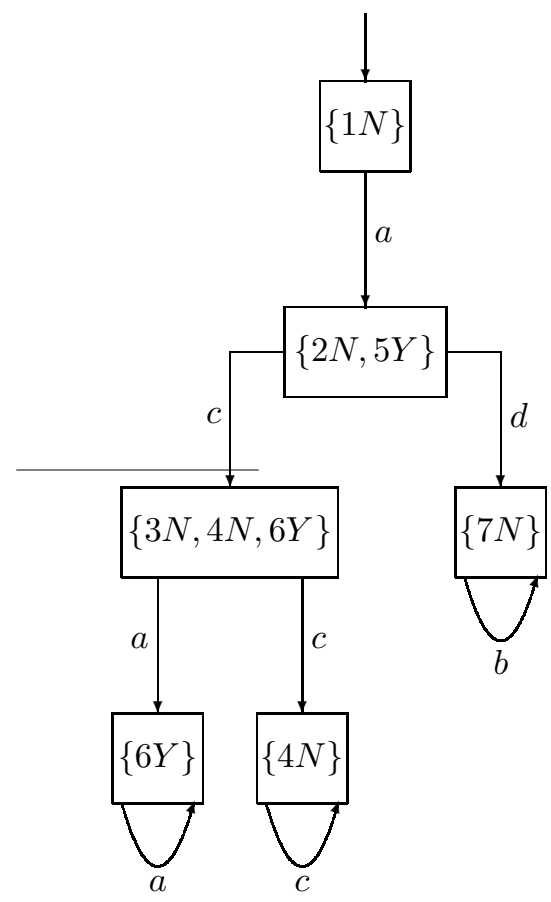

(a)

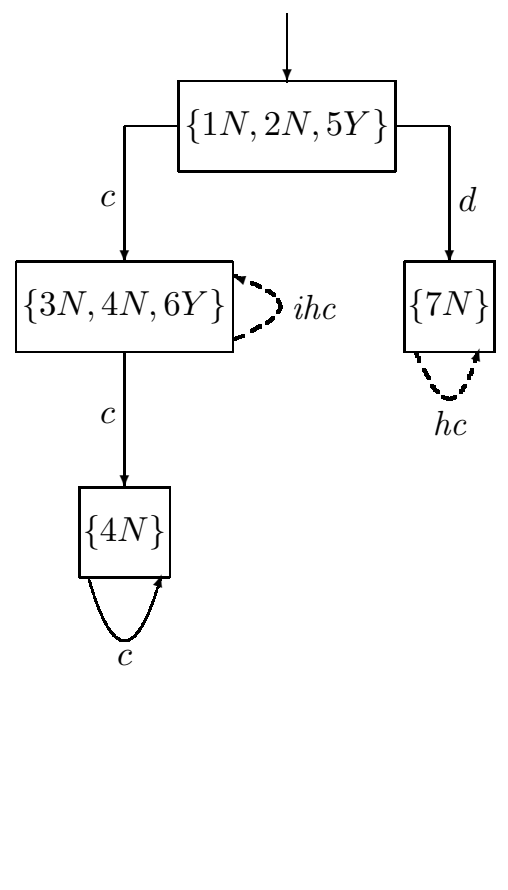

(b)

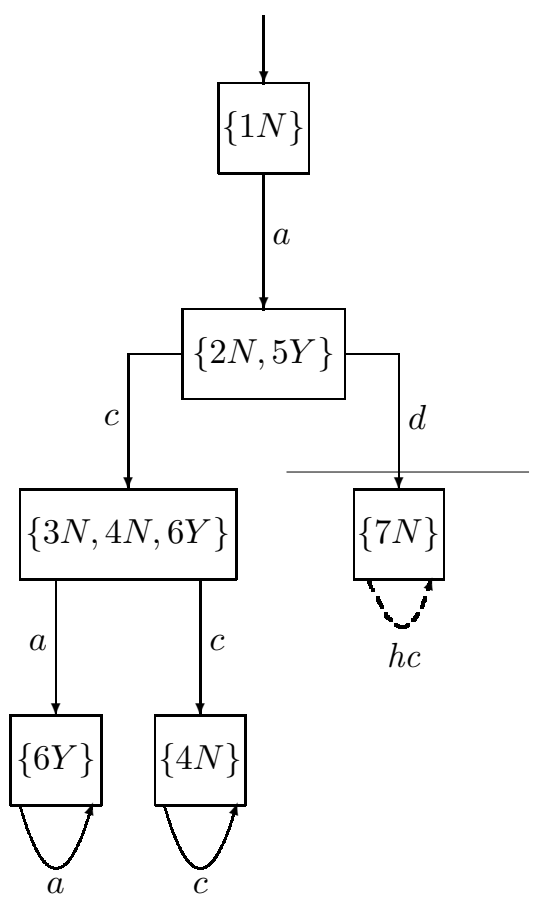

(c)

Figura 9: Diagnosticador $G_{d}$ (a) e os diagnosticadores parciais $G_{d}^{\prime}$ (b) e $G_{d}^{\prime \prime}$ (c) para os conjuntos de eventos observáveis $\Sigma_{o}^{\prime}=\{c, d\}$ e $\Sigma_{o}^{\prime \prime}=\{a, c, d\}$, respectivamente.

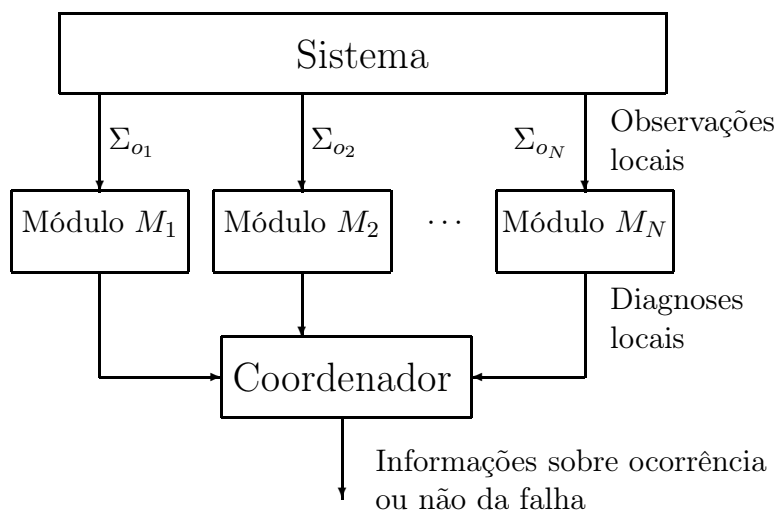

Figura 10: Estrutura descentralizada com coordenação.

dor para que este faça a diagnose. Observe que, para cada trajetória do $\mathrm{SED}, C$ é representada por um conjunto de informações que é dependente do protocolo empregado. Então, a informação passada ao coordenador para a diagnose é chamada certa se, baseada em $C$, o coordenador está certo da ocorrência de uma falha em $\Sigma_{f}$. Consequentemente, a definição 2 pode ser modificada para abranger sistemas descentralizados com coordenação, da forma apresentada a seguir (Debouk et al., 2000).

Definição 8 Uma linguagem $L$ viva e prefixo-fechada é di- agnosticável em relação a um protocolo, um conjunto de projeções $P_{o_{i}}, i=1, \ldots, N$, e um conjunto de falhas $\Sigma_{f}=$ $\left\{\sigma_{f}\right\}$, se a seguinte condição for verificada:

$$
\begin{gathered}
(\exists n \in \mathbb{N})\left(\forall s \in \Psi\left(\Sigma_{f}\right)\right)(\forall t \in L / s)(\|t\| \geq n \\
\Rightarrow C \text { está certa }) .
\end{gathered}
$$

Assim como no caso da diagnose centralizada, a detecção de qualquer falha será efetuada pelo coordenador após um atraso finito de sua ocorrência.

O protocolo a ser considerado neste tutorial foi proposto por Debouk et al. (2000) e consiste na implementação de um diagnosticador parcial em cada módulo, sendo o estado do diagnosticador, após a ocorrência de um evento observável, a informação para diagnose, na qual o módulo irá se basear para inferir sobre a ocorrência de falhas. Quando um módulo observa um evento que leva a um estado certo no seu diagnosticador, ele comunica a ocorrência da falha ao coordenador. Da parte do coordenador, a declaração definitiva da ocorrência de uma falha dar-se-á sempre que pelo menos um módulo reportar a ocorrência da falha; por outro lado ele se manterá "em silêncio" quando nenhum dos módulos reportar a ocorrência de falha. Note que esse protocolo pode ser visto como uma extensão da diagnose centralizada para o caso de diagnose descentralizada com coordenação e, por essa razão, 
no decorrer deste artigo, será referida simplesmente como codiagnose.

Para se abordar o problema da codiagnose, além das hipóteses A1 a A3, deve-se supor ainda que:

A5. $L$ não é diagnosticável em relação a $P_{o_{i}}, i=$ $1,2, \ldots, N$.

A6. A comunicação entre os módulos e o coordenador é confiável, isto é, todas as mensagens enviadas por todos os módulos são recebidas pelo coordenador corretamente e na mesma ordem do envio.

A hipótese A5 exclui o caso trivial em que um módulo possa vir a desempenhar o papel de diagnosticador centralizado e a hipótese A6 foi removida por Basilio e Lafortune (2009). É importante ressaltar que em Debouk et al. (2000), uma hipótese adicional bastante restritiva foi feita: $G$ não possui nenhum ciclo de eventos não-observáveis com relação a $\Sigma_{o_{i}}$, $i=1,2, \ldots, N$. Essa hipótese foi aqui removida, sendo os ciclos de eventos não-observáveis em relação a $\Sigma_{O_{i}}$ considerados como ciclos escondidos.

A idéia por trás do problema da codiagnose é que toda sequência $s \in \Psi\left(\Sigma_{f}\right)$ deve ser diagnosticada por, pelo menos, um diagnosticador parcial. Uma sequência $s \in \Psi\left(\Sigma_{f}\right)$ que não for diagnosticada por nenhum diagnosticador parcial será denominada uma sequência totalmente ambígua, cuja definição é dada a seguir.

Definição 9 (Sequência totalmente ambígua) Uma sequência $s \in L$ será totalmente ambígua em relação às projeções $P_{o_{i}}, i=1,2, \ldots, N$, e à falha $\sigma_{f}$, se existirem $N$ sequências $s_{1}, s_{2}, \ldots, s_{N} \in L$, não necessariamente distintas, tais que

1) $\Sigma_{f} \in s$, porém $\Sigma_{f} \notin s_{i}, i=1,2, \ldots, N$;

2) $P_{o_{i}}(s)=P_{o_{i}}\left(s_{i}\right), i=1,2, \ldots, N$.

Consequentemente, a fim de se verificar se $L$ é diagnosticável em relação às projeções $P_{o_{i}}, i=1,2, \ldots, N$ e $\Sigma_{f}=\left\{\sigma_{f}\right\}$, basta se certificar da existência de sequências totalmente ambíguas. Com o intuito de se obter um teste para detectar a existência de sequências totalmente ambíguas, seja $G_{d_{i}}=$ $\left(X_{d_{i}}, \Sigma_{o_{i}}, f_{d_{i}}, \Gamma_{d_{i}}, x_{0_{d_{i}}}\right)$ o diagnosticador parcial para o módulo $M_{i}, i=1,2, \ldots, N$, e suponha que $G_{d}$ denote o diagnosticador centralizado. Considere o diagnosticador $G_{\text {test }_{N}}$ definido da seguinte forma:

$$
G_{\text {test }_{N}}=\left(\|_{i=1}^{N} G_{d_{i}}\right) \| G_{d} .
$$

Pode-se, portanto, concluir que

$$
L\left(G_{\text {test }_{N}}\right)=\left\{\bigcap_{i=1}^{N} P_{o_{i}}^{-1}\left[L\left(G_{d_{i}}\right)\right]\right\} \bigcap L\left(G_{d}\right) .
$$

Dessa forma,

$$
L\left(G_{\text {test }_{N}}\right)=L\left(G_{d}\right),
$$

que mostra que $G_{\text {test }_{N}}$ provê os meios necessários para se identificar o estado atual dos diagnosticadores parciais $G_{d_{i}}$, $i=1,2, \ldots, N$, após a execução de qualquer sequência de $L$. Observe ainda que o estado $x_{t_{N}}$ de $G_{\text {test }_{N}}$ tem a seguinte estrutura:

$$
x_{t_{N}}=\left(x_{d_{1}}, x_{d_{2}}, \ldots, x_{d_{n}}, x_{d}\right),
$$

em que $x_{d_{i}} \in X_{d_{i}}$ e $x_{d} \in X_{d}$.

As definições de estado incerto e ciclo indeterminado são estendidas para codiagnose da seguinte forma.

Definição 10 Um estado $x_{t}$ de $G_{\text {test }_{N}}$ é certo se $x_{d}$ é certo e $x_{d_{i}}$ for certo para algum $i \in\{1,2, \ldots, N\}$, e é incerto se $x_{d}$ é certo e $x_{d_{i}}$ for incerto para todo $i \in\{1,2, \ldots, N\}$.

Definição 11 Um ciclo em $G_{\text {test }_{N}}$ será indeterminado se todos os correspondentes ciclos em $G_{d_{i}}, i=1,2, \ldots, N$ (incluindo ciclos escondidos) forem indeterminados.

De acordo com a definição 9, uma sequência totalmente ambígua $s$ é uma sequência $s \in \Psi\left(\Sigma_{f}\right)$ que leva a ciclos indeterminados em todos os diagnosticadores parciais $G_{d_{i}}$. Além disso, em face da hipótese A4, para todo $s \in \Psi\left(\Sigma_{f}\right)$, existirá sempre uma sequência de comprimento finito $t$ tal que $s t$ leva a um evento certo de $G_{d}$. Consequentemente, conforme mencionado em Debouk et al. (2000), $G_{\text {test }_{N}}$ pode ser usado para verificar a existência de sequências totalmente ambíguas.

Teorema 4 Uma linguagem $L$, viva e prefixo-fechada, será codiagnosticável em relação ao conjunto de projeções $P_{o_{i}}$ : $\Sigma^{*} \rightarrow \Sigma_{o_{i}}^{*}, i=1,2, \ldots, N$ e $\Sigma_{f}=\left\{\sigma_{f}\right\}$ se, e somente se, $G_{\text {test }_{N}}$ não possuir ciclos indeterminados.

A prova apresentada em Debouk et al. (2000) é também válida aqui, uma vez que a definição 11 foi modificada para acomodar também os ciclos escondidos indeterminados.

Exemplo 8 Considere o autômato $G$ cujo diagrama de transição de estados está representado na figura 7(a). Suponha que os conjuntos de eventos observáveis e não-observáveis de $G$ sejam $\Sigma_{o}=\{a, b, c\}$ e $\Sigma_{u o}=\Sigma_{f}=\left\{\sigma_{f}\right\}$, respectivamente. O diagnosticador centralizado $G_{d}$ para $G$ está representado na figura 11, que mostra que a linguagem $L$ gerada por $G$ pode ser diagnosticada em relação a $P_{o}: \Sigma^{*} \rightarrow \Sigma_{o}^{*}$ e $\Sigma_{f}$. Suponha agora que nem todos os eventos observáveis estejam disponíveis simultaneamente em um mesmo lugar. Assim, para contornar esse problema, um diagnosticador descentralizado com coordenação composto, por exemplo, por dois módulos, deve ser construído para detectar a ocorrência de $\sigma_{f}$. Considere as seguintes situações: 


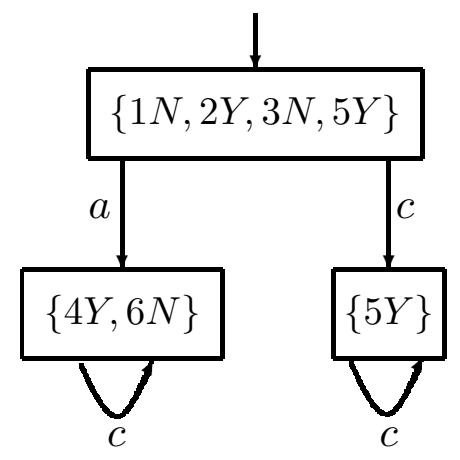

(a)

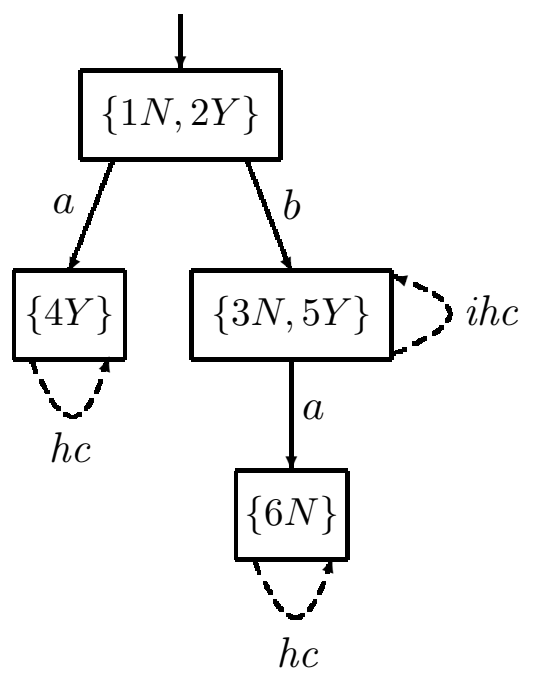

(b)

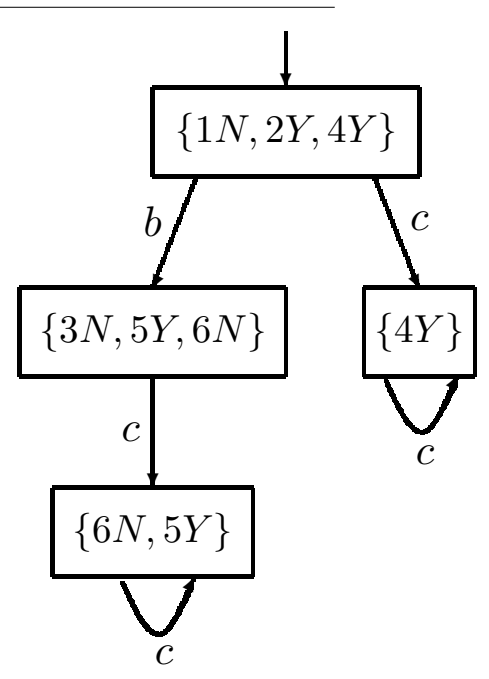

(c)

Figura 12: Diagnosticadores parciais para o autômato $G$ da figura 7(a) para os seguintes conjuntos de eventos observáveis: (a) $\Sigma_{o_{1}}=\{a, c\}$; (b) $\Sigma_{o_{2}}=\{a, b\}$; (c) $\Sigma_{o_{3}}=\{b, c\}$.

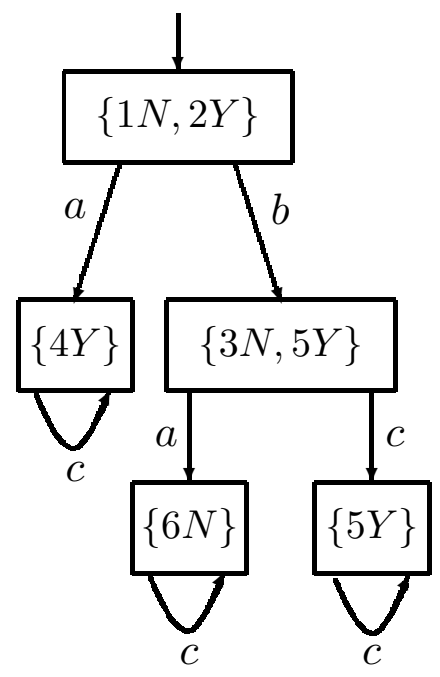

Figura 11: Diagnosticador centralizado para $G$.

1o caso. Os conjuntos de eventos observáveis são $\Sigma_{o_{1}}=$ $\{a, c\}$ e $\Sigma_{o_{2}}=\{a, b\}$. Os correspondentes diagnosticadores parciais $G_{d_{1}}$ e $G_{d_{2}}$ estão representados nas figuras 12(a) e (b), e o diagnosticador teste $G_{\text {test }_{3}}=G_{d_{1}}\left\|G_{d_{2}}\right\| G_{d}$ pode ser visto nas figura 13(a). Observe que embora as linguagens geradas por $G$ e $G_{d}$ sejam vivas, a linguagem gerada por $G_{d_{2}}$ não é viva. Isso ocorre porque a linguagem gerada por $G_{d}$ se mantém viva após os estados $\{4 Y\}$ e $\{6 N\}$ pela ocorrência do evento $c$, que se tornou não-observável para o módulo 2; criando, consequentemente, ciclos escondidos nos estados $\{4 Y\}$ e $\{6 N\}$. Observe ainda que, além desses ciclos, há ainda em $G_{d_{2}}$ um outro ciclo escondido no estado
$\{3 N, 5 Y\}$, também devido ao evento $c$. A presença de um ciclo indeterminado escondido em $G_{d_{2}}$ não altera a codiagnose do sistema, uma vez que, conforme pode ser visto na figura 13(a), $G_{\text {test }_{3}}$ não possui ciclos indeterminados, e, portanto, $L$ é diagnosticável em relação a $P_{o_{i}}: E^{*} \rightarrow \Sigma_{o_{i}}, i=1,2$, e $\Sigma_{f}$.

$2^{o}$ caso. Os conjuntos de eventos observáveis são $\Sigma_{o_{2}}=$ $\{a, b\}$ e $\Sigma_{o_{3}}=\{b, c\}$. Os correspondentes diagnosticadores parciais $G_{d_{2}}$ e $G_{d_{3}}$ estão representados nas figuras 12 (b) e (c), e o diagnosticador de teste $G_{\text {test }_{3}}^{\prime}=$ $G_{d_{2}}\left\|G_{d_{3}}\right\| G_{d}$ pode ser visto na figura $13(\mathrm{~b})$. Note que o estado $\{3 N, 5 Y ; 6 N, 5 Y ; 5 Y\}$ de $G_{\text {test }_{3}}^{\prime}$ tem um ciclo indeterminado formado com o estado $\{6 N, 5 Y\}$ de $G_{d_{3}}$, e um ciclo indeterminado escondido formado com o estado $\{3 N, 5 Y\}$ de $G_{d_{2}}$. Dessa forma, pode-se concluir que $L$ é não diagnosticável em relação a $P_{o_{i}}: \Sigma^{*} \rightarrow \Sigma_{o_{i}}^{*}, i=2,3$ e $\Sigma_{f}$. Isso se deve ao fato de, das duas sequências arbitrariamente longas $s_{1}=\sigma_{f} a c^{n}$ e $s_{2}=\sigma_{f} b c^{n}(n \in \mathbb{N})$ que contêm $\sigma_{f}$, somente a sequência $s_{1}$ pode ser detectada nessa configuração; observe que enquanto $P_{o_{2}}\left(s_{1}\right)$ e $P_{o_{3}}\left(s_{1}\right)$ levam ambos a estados certos de $G_{d_{2}}$ e $G_{d_{3}}, P_{o_{2}}\left(s_{2}\right)$ e $P_{o_{3}}\left(s_{2}\right)$ levam a estados incertos tanto em $G_{d_{2}}$ quanto em $G_{d_{3}}$. Dessa forma, $s_{2}$ é uma sequência totalmente ambígua.

Conforme visto acima a linguagem gerada pelo autômato da figura 7(a) é codiagnosticável em relação a $\Sigma_{f}, P_{o_{1}}, P_{o_{2}}$. Na prática a diagnose de $L(G)$ é feita da seguinte forma. Constroem-se os diagnosticadores parciais $G_{d_{1}}$ e $G_{d_{2}}$ e um coordenador central que recebe informações dos diagnosticadores parciais. Deve-se observar que os diagnosticadores $G_{d_{1}}$ e $G_{d_{2}}$ não se comunicam entre si. Caso ocorra, 


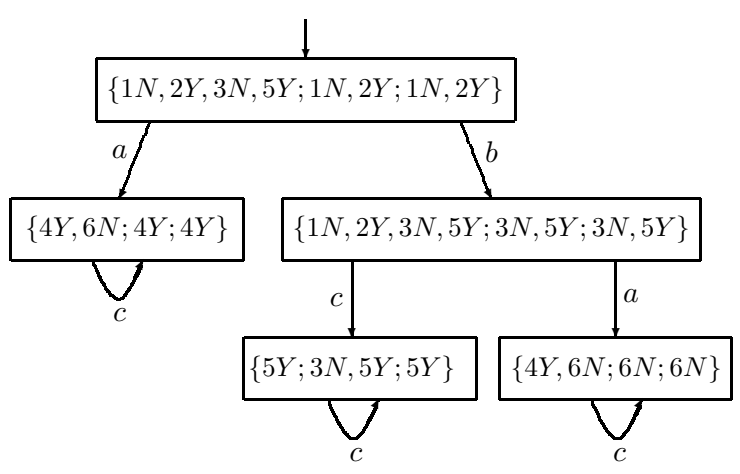

(a)

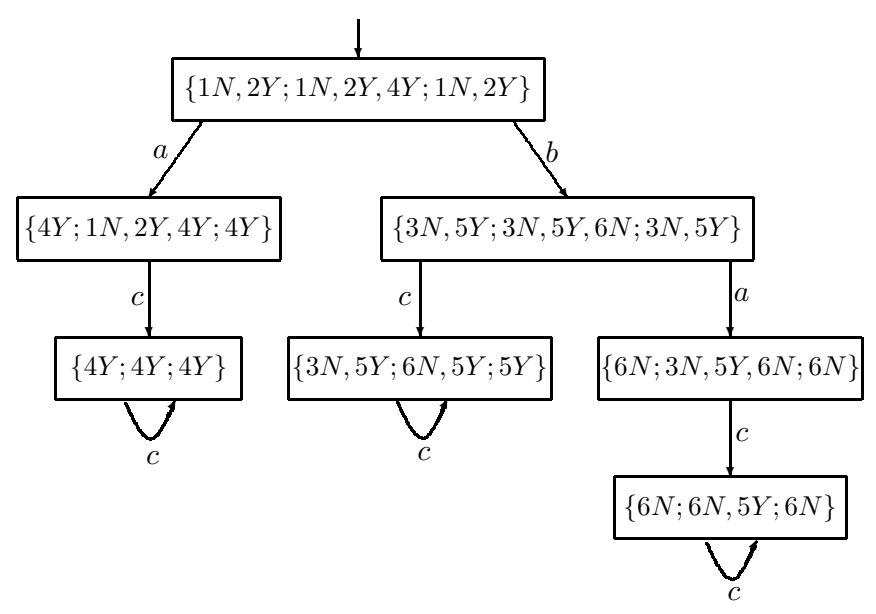

(b)

Figura 13: Diagnosticadores de teste para o autômato $G$ da figura 7(a): $G_{\text {test }_{3}}=G_{d_{1}}\left\|G_{d_{2}}\right\| G_{d}$ (a); $G_{\text {test }_{3}}^{\prime}=G_{d_{2}}\left\|G_{d_{3}}\right\| G_{d}$ (b).

por exemplo, o evento $b$, ambos os diagnosticadores parciais permanecerão em silêncio visto que estarão nos estados $\{1 N, 2 Y, 3 N, 5 Y\}$ e $\{3 N, 5 Y\}$. Caso o próximo evento a ocorrer seja o evento $a$, ambos os diagnosticadores parciais permanecerão em silêncio pois $G_{d_{1}}$ mudará para o estado $\{4 Y, 6 N\}$ (incerto), e $G_{d_{2}}$ passará para o estado $\{6 N\}$, assim permanecendo indefinidamente. Se o segundo evento a ocorrer for o evento $c$, o diagnosticador parcial $G_{d_{1}}$ mudará para o estado certo $\{5 Y\}$ e comunicará a ocorrência da falha ao coordenador, que, então, declarará a ocorrência da falha.

\section{VERIFICADOR}

O teste desenvolvido na seção anterior para verificação da diagnosticabilidade de linguagens geradas por SEDs se baseia na construção de um autômato determinístico denominado diagnosticador. Uma vez construído o diagnosticador, a diagnosticabilidade da linguagem pode ser testada com complexidade polinomial em relação à cardinalidade do espaço de estado do diagnosticador. Contudo, a cardinalidade do espaço de estados do diagnosticador é, no pior caso, exponencial, tendo em vista que ao agrupar estados de $G$ para chegar a um estado de $G_{d}$ obtém-se, no pior caso,

$$
\left|X_{d}\right|=2^{2|X|},
$$

ou seja, $O\left(2^{|X|}\right)$. Para solucionar o problema da complexidade exponencial do espaço de estados, foram propostos os chamados autômatos verificadores ( Jiang et al. (2001), Yoo e Lafortune (2002) e Qiu e Kumar (2006) para o caso da diagnose centralizada e Qiu e Kumar (2006), Wang et al. (2007) e Basilio e Lafortune (2009) para codiagnose), cujos espaços de estados dos autômatos são polinomiais em relação à car- dinalidade do espaço de estados de $G$. O teste proposto por Qiu e Kumar (2006) é consideravelmente mais simples e intuitivo que aqueles apresentados em Jiang et al. (2001), Yoo e Lafortune (2002), Wang et al. (2007) e Basilio e Lafortune (2009) e, por essa razão, será apresentado em detalhes nessa seção.

\subsection{Verificador centralizado}

Seja $G$ o autômato determinístico da equação (6). O verificador centralizado proposto por Qiu e Kumar (2006) é construído de acordo com o seguinte algoritmo.

Algoritmo 2 (Construção do verificador centralizado)

Passo 1: Construção do autômato $H^{C}$.

1. Construa um autômato $H_{0}$ que tenha um único estado e um único laço com todos os eventos de $\Sigma$ exceto os eventos do conjunto de falhas $\Sigma_{f}$, isto é, $\Sigma \backslash \Sigma_{f}$;

2. Calcule $H:=G \times H_{0}$, em que $H=\left(X_{H}, \Sigma, f_{H}, \Gamma_{H}\right.$, $\left.x_{0_{H}}\right)$;

3. Obtenha o autômato ${ }^{2} H^{C}=\left(X_{H^{C}}, \Sigma, f_{H^{C}}, \Gamma_{H^{C}}, x_{0_{H^{C}}}\right)$ em que $X_{H^{C}}=X_{H} \cup\{F\}$, sendo que $F$ denota o estado de falha e cuja função de transição $f_{H^{C}}$ é definida da seguinte forma:

$$
f_{H^{C}}\left(x_{H^{C}}, \sigma\right)= \begin{cases}f_{H}\left(x_{H}, \sigma\right) & , \text { se } \sigma \in \Gamma\left(x_{H}\right), \\ F & , \text { caso contrário. }\end{cases}
$$

$f_{H^{C}}(F, \sigma)=F$ para todo $\sigma \in \Sigma$.

\footnotetext{
${ }^{2}$ Note que o autômato $H^{C}$ somente não representa o complementar de $H$ pelo simples fato do estado $F$ não ser marcado.
} 
Passo 2: Construção do verificador $G_{V}$.

$\mathrm{O}$ verificador $G_{V}$ é uma sêxtupla definida como:

$$
G_{V}=\left(X_{V}, \Sigma_{V}, f_{V}, \Gamma_{V}, x_{0_{V}}\right),
$$

em que

- $X_{V}=X \times X_{H^{C}} \times X_{H}$;

- $x_{0_{V}}=\left(x_{0}, x_{0_{H}}, x_{0_{H}}\right)$;

- $\Sigma_{V}=\bar{\Sigma} \times \bar{\Sigma}_{H}$, sendo $\bar{\Sigma}=\Sigma \cup\{\epsilon\}$ e $\bar{\Sigma}_{H}=\Sigma_{H} \cup\{\epsilon\}$;

- sendo $x_{V}=\left(x, x_{H^{C}}, x_{H}\right) \in X_{V}$ e $\sigma_{V}=\left(\sigma, \sigma_{H}\right) \in$ $\Sigma_{V} \backslash\{\epsilon \epsilon\}$, então $f_{V}: X_{V} \times \Sigma_{V} \rightarrow X_{V}$ é definida como

$$
f_{V}\left(x_{V}, \sigma_{V}\right):=\left(f(x, \sigma), f_{H^{C}}\left(x_{H^{C}}, \sigma\right), f_{H}\left(x_{H}, \sigma_{H}\right)\right)
$$

se e somente se

$$
\left(P_{o}(\sigma)=P_{o}\left(\sigma_{H}\right)\right) \wedge\left(f(x, \sigma) \neq \emptyset \vee f_{H}\left(x_{H}, \sigma_{H}\right) \neq \emptyset\right) .
$$

Note inicialmente que o autômato $H$ é um subautômato de $G$ que possui todas sequências de $L(G)$ que não contêm o evento $\sigma_{f}$. Assim, toda sequência de $L(G)$ que não possuir a falha $\sigma_{f}$ deverá pertencer a $L(H)$. Além disso, de acordo com a construção de $G_{V}$ (passo 2 do algoritmo 2), o seu estado possui três componentes $\left(x, x_{H^{C}}, x_{H}\right)$ e a função de transição de estados é definida utilizando-se uma combinação de eventos $\sigma \sigma_{H}$, em que $\sigma \in G$ e $\sigma_{H} \in H$, não necessitando um evento de $H^{C}$, uma vez que $f_{H^{C}}$ é total em seu domínio. Portanto, as sequências geradas em $G_{V}$ são as sequências $u$ e $v$ tais que $u \in L(G)$ e $v \in L(H)$. Como, de acordo com o passo 2, deve-se ter $P_{o}(u)=P_{o}(v)$, então $L(G)$ não será diagnosticável com relação a $P_{o}$ e $\Sigma_{f}$ se existir uma sequência $v \in L(H)$ que não contenha a falha $\sigma_{f}$ e que tenha a mesma projeção que uma outra sequência $u \in L(G)$ tal que $\sigma_{f} \in u$. Isso permite verificar a diagnosticabilidade da linguagem gerada por $G$ com relação a $P_{o}$ e $\Sigma_{f}$ conforme mostra o resultado a seguir.

Teorema 5 (Qiu e Kumar, 2006) Sejam $G=$ $\left(X, \Sigma, \Gamma, f, x_{0}\right)$ e $H=\left(X_{H}, \Sigma, f_{H}, \Gamma_{H}, x_{0_{H}}\right)$ autômatos que geram as seguintes linguagens $L(G)=L=\bar{L}$ e $L(H)=K=\bar{K}$, respectivamente e $K \subseteq L$. A ocorrência de sequências pertencentes a $L-K$ não será diagnosticável com relação a $P_{o}$, se e somente se existir um ciclo $c l^{T}=\left(x_{V_{k}}, \sigma_{V_{k}}, x_{V_{k+1}}, \ldots, x_{V_{l}}, \sigma_{V_{l}}, x_{V_{k}}\right)$ no autômato verificador $G_{V}=\left(X_{V}, \Sigma_{V}, f_{V}, \Gamma_{V}, x_{0_{V}}\right)$ tal que

$$
\left\{\exists i \in[k, k+1, \ldots, l]:\left(x_{i_{H C}}=F\right) \wedge\left(\sigma_{i} \neq \epsilon\right)\right\}
$$

em que $l>k \geq 0$ e $x_{i_{H} C}$ é a segunda coordenada do estado $x_{i_{V}}$, e $\sigma_{i}$ é a primeira coordenada de $\sigma_{V_{i}} \in \Sigma_{V}$.

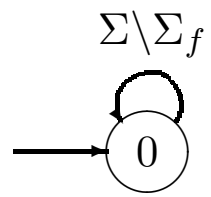

(a)

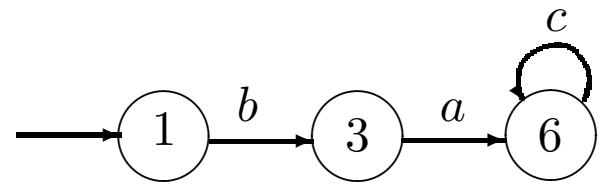

(b)

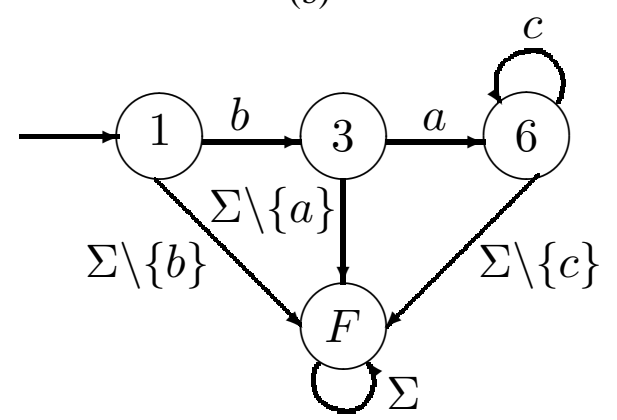

(c)

Figura 14: Autômato $H_{0}$ (a), autômato $H=G \times H_{0}$ (b) e autômato $H^{C}$ (c).

Exemplo 9 Para ilustrar a construção dos verificadores, considere o autômato $G$ da subseção 4.3 , cujo diagrama de transição de estados está representado na figura 7(a). Suponha que o conjunto de eventos observáveis e não-observáveis de $G$ sejam $\Sigma_{o}=\{a, b, c\}$ e $\Sigma_{u o}=\Sigma_{f}=\left\{\sigma_{f}\right\}$, respectivamente. De acordo com o passo 1 do algoritmo 2, deve-se inicialmente construir o autômato $H_{0}$ mostrado na figura 14(a) e, em seguida, calcular $H$ cujo resultado está mostrado na figura 14(b), para finalmente obter o diagrama de transição de $H^{C}$ representado na figura 14(c). Uma vez obtidos os autômatos $H$ e $H^{C}$, pode-se obter o verificador apresentado na figura 15. O estado inicial do verificador centralizado $G_{V}$ tem como componentes os estados iniciais de $G, H^{C}$ e $H$; portanto $x_{0_{V}}=\{1,1,1\}$. Para se obter o conjunto de eventos ativos do estado inicial, deve-se observar a função dos eventos ativos de cada componente, isto é, $\Gamma\left(x_{0}\right)=\left\{\sigma_{f}, b, \epsilon\right\}$ e $\Gamma_{H}\left(x_{0_{H}}\right)=\{b, \epsilon\}$. Para satisfazer a propriedade $P_{o}(\sigma)=P_{o}\left(\sigma_{H}\right)$, imposta pelo passo 2 do algoritmo 2, deve-se ter $\Gamma_{G_{V}}\left(x_{0_{V}}\right)=\left\{\sigma_{f} \epsilon, b b\right\}$. Assim, $f_{V}\left(\{1,1,1\}, \sigma_{f} \epsilon\right)=\left\{f\left(1, \sigma_{f}\right), f_{H^{C}}\left(1, \sigma_{f}\right), f_{H}(1, \epsilon)\right\}=$ $\{2, F, 1\}$ e $f_{V}(\{1,1,1\}, b b)=\{3,3,3\}$. No estado $x_{V}=$ $\{2, F, 1\}$, as funções dos eventos ativos são $\Gamma(2)=\{a, b, \epsilon\}$ e $\Gamma_{H}(1)=\{b, \epsilon\}$. Como o evento $a$ é observável e não está ativo em $x_{H}=\{1\}$, então não pode pertencer a $\Gamma_{V}(\{2, F, 1\})$. Além disso como $b \in \bar{\Sigma}$ e $b \in \Gamma_{H}(1)$, então a única combinação de eventos que poderá ocorrer no estado $\{2, F, 1\}$ é $b b$, levando o verificador para o estado 


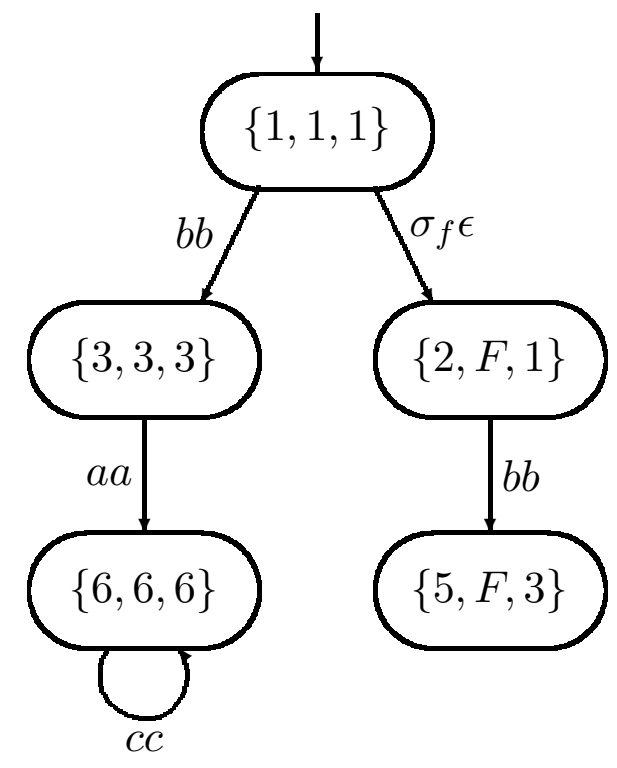

Figura 15: Verificador centralizado para $G$.

$\{5, F, 3\}$. Como, as funções dos eventos ativos de $\{5, F, 3\}$ são $\Gamma(5)=\{c, \epsilon\}$ e $\Gamma_{H}(3)=\{a, \epsilon\}$, não será possível satisfazer a propriedade $P_{o}(\sigma)=P_{o}\left(\sigma_{H}\right)$ no estado $\{5, F, 3\}$, e dessa forma não será possível definir qualquer transição a partir desse estado. Considere agora, o estado $\{3,3,3\}$. É fácil verificar que a única combinação de eventos possível é $a a$, levando assim ao estado $\{6,6,6\}$. Finalmente, a única combinação de eventos que pode ser definida a partir do estado $\{6,6,6\}$ é $c c$ que, quando ocorrer, fará com que o verificador permaneça nesse mesmo estado.

Observando a figura 15 é possível ver que não existe um ciclo $\mathrm{cl}^{T}$ contendo $x_{i_{H} C}=F$. Portanto, a linguagem $L$ gerada por $G$ será diagnosticável em relação a $P_{o}: \Sigma^{*} \rightarrow \Sigma_{o}^{*}$ e $\Sigma_{f}$. Note que esse resultado coincide com o obtido na subseção 4.3 com o auxílio de um diagnosticador.

\subsection{Verificador descentralizado}

Qiu e Kumar (2006) propuseram também um verificador descentralizado que é construído de forma semelhante ao algoritmo 2. A idéia básica é construir um autômato de teste que identifique sequências contendo falhas e as correspondentes sequências que não contenham falhas para cada módulo mas que possuam a mesma projeção. O passo 1 é mantido integralmente. Já o Passo 2 é modificado conforme algoritmo a seguir.

Algoritmo 3 (Construção do verificador descentralizado)

Passo 1: Idêntico ao Passo 1 do algoritmo 2.
Passo 2: Construção do verificador descentralizado $G_{V}$. $\mathrm{O}$ verificador $G_{V}$ é uma sêxtupla definida da seguinte forma:

$$
G_{V}=\left(X_{V}, \Sigma_{V}, f_{V}, \Gamma_{V}, x_{0_{V}}, X_{m_{V}}\right),
$$

em que

- $X_{V}=X \times X_{H^{C}} \times X_{H}^{1} \times \ldots \times X_{H}^{N}$;

- $x_{0_{V}}=\left(x_{0}, x_{0_{H} C}, x_{0_{H}}^{1}, \ldots, x_{0_{H}}^{N}\right)$;

- $\Sigma_{V}=\bar{\Sigma}_{H}^{N+1}$;

- sendo $x_{V}=\left(x, x_{H^{C}}, x_{H}^{1}, \ldots, x_{H}^{N}\right) \in X_{V}$ e $\sigma_{V}=$ $\left(\sigma, \sigma_{H}^{1}, \ldots, \sigma_{H}^{N}\right)$, então $f_{V}: X_{V} \times \Sigma_{V} \backslash\{\epsilon, \underbrace{\epsilon, \ldots, \epsilon}_{N}\} \rightarrow$ $X_{V}$ é definida como:

$$
\begin{aligned}
f_{V}\left(x_{V}, \sigma_{V}\right):=( & f(x, \sigma), f_{H^{C}}\left(x_{H^{C}}, \sigma\right), f_{H}\left(x_{H}^{1}, \sigma_{H}^{1}\right), \\
& \left.\ldots, f_{H}\left(x_{H}^{N}, \sigma_{H}^{N}\right)\right)
\end{aligned}
$$

se e somente se

$P_{o_{i}}(\sigma)=P_{o_{i}}\left(\sigma_{H}^{i}\right) \wedge\left(f(x, \sigma) \neq \emptyset \vee f_{H}\left(x_{H}^{i}, \sigma_{H}^{i}\right) \neq \emptyset, i=\right.$ $1, \ldots, N)$.

Assim como no verificador centralizado, a presença de ciclos que contenham $F$ na segunda componente no verificador levam à violação da diagnose conforme mostrado no teorema 5.

Exemplo 10 Para ilustrar a construção do verificador descentralizado, considere novamente o autômato $G$ da figura 7(a) e suponha que os conjuntos de eventos observáveis de cada módulo sejam $\Sigma_{o_{1}}=\{a, b\}$ e $\Sigma_{O_{2}}=\{b, c\}$. O passo 1 do algoritmo 2 é mantido no caso descentralizado, portanto $H_{0}, H, H^{C}$ são aqueles autômatos cujos diagramas de transição estão representados na figura 14 .

Com os autômatos $H$ e $H^{C}$, pode-se obter o verificador descentralizado $G_{V}$ apresentado na figura 16. O estado inicial de $G_{V}$ tem como componentes os estados iniciais de $G, H^{C}$ e $H$, e lembrando que existem dois módulos, então $N=2$ e, portanto, $x_{0_{V}}=\{1,1,1,1\}$. Para se obter o conjunto de eventos ativos do estado inicial, deve-se observar a função dos eventos ativos das componentes 1,3 e 4, uma vez que para todo estado $x_{H^{C}}$ de $H^{C}, \Gamma_{H^{C}}\left(x_{H^{C}}\right)=\Sigma$. Dessa forma, $\Gamma\left(x_{0}\right)=\left\{\sigma_{f}, b, \epsilon\right\}$ e $\Gamma_{H}\left(x_{0_{H}}^{1}\right)=\Gamma_{H}\left(x_{0_{H}}^{2}\right)=\{b, \epsilon\}$. Para satisfazer as condições $P_{o 1}(\sigma)=P_{o 1}\left(\sigma_{H}^{1}\right)$ e $P_{o 2}(\sigma)=$ $P_{o 2}\left(\sigma_{H}^{2}\right)$, impostas no passo 2 do algoritmo 3 , deve-se ter $\Gamma_{G_{V}}\left(x_{0_{V}}\right)=\left\{\sigma_{f} \epsilon \epsilon, b b b\right\}$. Assim, $f_{V}\left(\{1,1,1,1\}, \sigma_{f} \epsilon \epsilon\right)=$ $\left\{f\left(1, \sigma_{f}\right), f_{H^{C}}\left(1, \sigma_{f}\right), f_{H}(1, \epsilon), f_{H}(1, \epsilon)\right\}=\{2, F, 1,1\} \mathrm{e}$ $f_{V}(\{1,1,1,1\}, b b b)=\{3,3,3,3\}$. Para o estado $x_{V}=$ $\{2, F, 1,1\}$, tem-se que $\Gamma(2)=\{a, b, \epsilon\}$ e $\Gamma_{H}(1)=\{b, \epsilon\}$. Como o evento $a$ não está ativo em $H$ e é observável no 
primeiro módulo, não se conseguirá atender à propriedade $P_{o 1}(\sigma)=P_{o 1}\left(\sigma_{H}^{1}\right)$. Portanto, a única combinação de eventos que poderá ocorrer no estado $\{2, F, 1,1\}$ é $b b b$, levando o verificador do estado $\{2, F, 1,1\}$ para o estado $\{5, F, 3,3\}$. Como $\Gamma(5)=\{c, \epsilon\}$ e $\Gamma_{H}(3)=\{a, \epsilon\}$, e como $c$ não está ativo em $H$ e é observável no primeiro módulo, não se conseguirá atender à propriedade $P_{o 1}(\sigma)=P_{o 1}\left(\sigma_{H}^{1}\right)$. Além disso, como $a$ é não-observável no segundo módulo e para atender as propriedades $P_{o 1}(\sigma)=P_{o 1}\left(\sigma_{H}^{1}\right)$ e $P_{o 2}(\sigma)=$ $P_{o 2}\left(\sigma_{H}^{2}\right)$, deve-se ter $\Gamma_{G_{V}}(\{5, F, 3,3\})=\{\epsilon \epsilon a\}$. Assim, $f_{V}(\{5, F, 3,3\}, \epsilon \epsilon a)=\{5, F, 3,6\}$. Note que como $\Gamma(5)=\{c, \epsilon\}, \Gamma_{H}(3)=\{a, \epsilon\}$ e $\Gamma_{H}(6)=\{c, \epsilon\}$, e uma vez que o evento $c$ está ativo em $G$ e só é observável no segundo módulo, então para satisfazer as proprieda$\operatorname{des} P_{o 1}(\sigma)=P_{o 1}\left(\sigma_{H}^{1}\right)$ e $P_{o 2}(\sigma)=P_{o 2}\left(\sigma_{H}^{2}\right)$, deve-se ter $\Gamma_{G_{V}}(\{5, F, 3,6\})=\{c \epsilon c\}$ gerando um autolaço no estado $\{5, F, 3,6\}$. Considere agora, o estado $\{3,3,3,3\}$. Como $\Gamma(3)=\{a, \epsilon\}$ e $\Gamma_{H}(3)=\{a, \epsilon\}$, então as combinações de eventos possíveis que satisfazem as propriedades $P_{o 1}(\sigma)=$ $P_{o 1}\left(\sigma_{H}^{1}\right)$ e $P_{o 2}(\sigma)=P_{o 2}\left(\sigma_{H}^{2}\right)$ são $\epsilon \epsilon a, a a a, a a \epsilon$, levando aos estados $\{3,3,3,6\},\{6,6,6,6\}$ e $\{6,6,6,3\}$, respectivamente. Em $\{3,3,3,6\}$, a única combinação de eventos possível é $a a \epsilon$, que leva ao estado $\{6,6,6,6\}$. $\operatorname{Em}\{6,6,6,3\}$, podem ocorrer $\epsilon \epsilon a$ que leva ao estado $\{6,6,6,6\}$ e $\epsilon c \epsilon$ que leva ao próprio estado. Finalmente, as combinações de eventos que podem ser definidas a partir do estado $\{6,6,6,6\}$ são $c c c, c \epsilon c$ e $\epsilon c \epsilon$ que, quando ocorrerem, farão com que o verificador permaneça no mesmo estado.

Note que o estado $\{5, F, 3,6\}$ de $G_{V}$ tem um ciclo $c l^{T}$ contendo $x_{i_{H}}=F$ e $\sigma_{V_{i}}=c \epsilon c$. Dessa forma, pode-se concluir que $L$ não é diagnosticável em relação a $P_{o_{i}}: \Sigma^{*} \rightarrow \Sigma_{o_{i}}$, $i=1,2$ e $\Sigma_{f}$. Isso se deve ao fato da sequência arbitrariamente longa $s=\sigma_{f} b c^{n}$ quando projetada em $P_{o_{1}}(s)$ e $P_{o_{2}}(s)$ poder ser confundida com as sequências $b$ e $b a c^{n}$ que não contêm $\sigma_{f}$. Dessa forma, $s$ é uma sequência totalmente ambígua.

\section{COMENTÁRIOS FINAIS}

O objetivo principal deste tutorial foi apresentar os conceitos básicos e os resultados principais para o estudo da diagnose de falhas de SEDs. Uma breve revisão dos conceitos de linguagem e autômatos foi também realizada com vistas a tornar o artigo autocontido. Para aqueles que não são familiarizados com a teoria de SEDs, sugere-se consultar Cassandras e Lafortune (2008) e Hopccroft et al. (2007). A revisão bibliográfica que foi realizada teve como intuito principal dar uma visão geral dos principais problemas que estão sendo abordados no que se refere à diagnose de falhas de SEDs e prover o leitor com as principais referências bibliográficas necessárias, caso ele deseje se aprofundar em qualquer um dos assuntos descritos na introdução. Por essa razão, deu-se

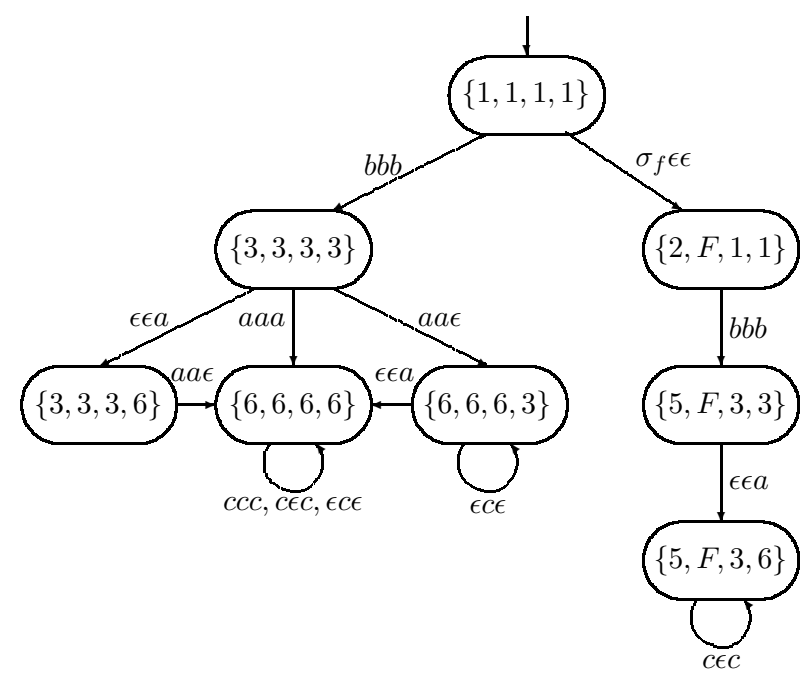

Figura 16: Verificador descentralizado para $G$.

preferência às publicações apresentadas em revistas científicas, estando assim longe de poder ser esgotada neste tutorial.

Entre os principais conceitos aqui apresentados, merecem destaque as definições de diagnosticabilidade e codiagnosticabilidade. Nesse sentido, condições necessárias e suficientes tanto para a diagnosticabilidade quanto para a codiagnosticabilidade foram apresentadas utilizando-se diagnosticadores e verificadores. Resultados recentes sobre diagnose com observação parcial foram também apresentados, destacandose os conceitos de ciclos escondidos e uma metodologia para a obtenção de diagnosticadores centralizados com observação parcial a partir do diagnosticador centralizado que utiliza todos os eventos observáveis do sistema (Basilio e Lafortune, 2009). Os diagnosticadores, embora tenham espaço de estado que, no pior caso, tem cardinalidade exponencial em relação à cardinalidade do espaço de estado da planta podem ser usados para a diagnose online (Sampath et al., 1996; Simsek et al., 1999; Sampath, 2001), enquanto que os verificadores podem somente ser usados na análise da diagnosticabilidade. Vale a pena ressaltar que o verificador aqui apresentado é um autômato não-determinístico; um novo verificador que, além de ser determinístico e ter menor complexidade computacional que os algoritmos encontrados na literatura, foi recentemente desenvolvido por Moreira et al. (2010).

Diagnose de falhas em SEDs representa um campo frutífero para investigação. Entre possíveis tópicos de pesquisa nessa área poder-se-ia citar: (i) a diagnose robusta em SEDs em relação a perdas de observabilidade de eventos, já que neste tutorial foi suposto que todos os sensores que registram as ocorrências dos eventos funcionam perfeitamente. Caso alguns dos sensores que provejam informações sobre ocorrências de eventos falharem, o diagnosticador pode estacionar 
em um determinado estado ou, até mesmo, dar uma informação incorreta em relação à ocorrência da falha. Pesquisas nessa área estão sendo realizadas pelos autores e os resultados já obtidos deram origem a artigos submetidos para publicação (Lima et al., 2010; Carvalho et al., 2010); (ii) alocação ótima de sensores, visando minimizar custos, sem, contudo, violar a especificação de tempo admissível entre a ocorrência da falha e a sua identificação pelo diagnosticador; (iii) diagnose em SEDs estocásticos, como continuação do trabalho iniciado por Thorsley e Teneketzis (2005); e (iv) controle supervisório em SEDs com tolerância a falhas (Paoli et al., 2008).

\section{AGRADECIMENTOS}

Os autores gostariam de agradecer aos revisores anônimos pela revisão cuidadosa e pelas sugestões para o aprimoramento desse artigo, ao CNPq e à FAPERJ pelo apoio financeiro.

\section{REFERÊNCIAS}

Alur, R. e Dill, D. L. (1994). A theory of timed automata, Theoretical Computer Science 126(2): 183-235.

Basile, F., Chiacchio, P. e De Tommasi, G. (2009). An efficient approach for online diagnosis of discrete event systems, IEEE Transactions on Automatic Control 54(4): 748-759.

Basilio, J. C. e Lafortune, S. (2009). Robust codiagnosability of discrete event systems, Proceedings of the American Control Conference, St. Louis, Missouri, pp. 22022209.

Belohlavek, R. (2002). Determinism and fuzzy automata, Information Sciences 143(1-4): 205-209.

Benveniste, A., Fabre, E., Haar, S. e Jard, C. (2003). Diagnosis of asynchronous discrete-event systems: a net unfolding approach, IEEE Transactions on Automatic Control 48(5): 714 - 727 .

Cabasino, M., Giua, A., Lafortune, S. e Seatzu, C. (2009). Diagnosability analysis of unbounded petri nets, Decision and Control, 2009 held jointly with the 2009 28th Chinese Control Conference. CDC/CCC 2009. Proceedings of the 48th IEEE Conference on, pp. $1267-1272$.

Carvalho, L. K., Basilio, J. C. e Moreira, M. V. (2010). Diagnose falhas de sistemas a eventos discretos sujeitos a perdas intermitentes de sensores, XVIII Congresso Brasileiro de Automática, Bonito, MS. (submetido para apresentação).

Cassandras, C. G. e Lafortune, S. (2008). Introduction to Discrete Event Systems, 2nd edn, Spirnger, Boston.
Chen, Y.-L. e Provan, G. (1997). Modeling and diagnosis of timed discrete event systems - a factory automation example, Proceedings of the American Control Conference, Vol. 1, Albuquerque, New Mexico, pp. 31-36.

Chung, S.-L., Wu, C.-C. e Jeng, M. (2003). Failure diagnosis: A case study on modeling and analysis by Petri nets, Proceedings of the IEEE International Conference on Systems, Man and Cybernetics, Vol. 3, Washington, pp. 2727-2732.

Contant, O., Lafortune, S. e Teneketzis, D. (2004). Diagnosis of intermittent faults, Discrete Event Dynamic Systems: Theory And Applications 14(2): 171-202.

Contant, O., Lafortune, S. e Teneketzis, D. (2006). Diagnosability of discrete event systems with modular structure, Discrete Event Dynamic Systems: Theory And Applications 16(1): 9-37.

David, R. e Alla, H. (2005). Discrete, Continuous, and Hybrid Petri Nets, Springer, New York, NY.

Debouk, R., Lafortune, S. e Teneketzis, D. (2000). Coordinated decentralized protocols for failure diagnosis of discrete event systems, Discrete Event Dynamic Systems: Theory and Applications 10: 33-86.

Dotoli, M., Fanti, M. P., Mangini, A. M. e Ukovich, W. (2009). On-line fault detection in discrete event systems by petri nets and integer linear programming, $A u$ tomatica 45(11): 2665-2672.

Gaubert, S. e Giua, A. (1999). Petri net languages and infinite subsets of n-m, Journal Of Computer And System Sciences 59(3): 373-391.

Genc, S. e Lafortune, S. (2007). Distributed diagnosis of place-bordered Petri nets, IEEE Transactions on Automation Science and Engineering 4(2): 206-219.

Giua, A. e Seatzu, C. (2005). Fault detection for discrete event systems using Petri nets with unobservable transitions, Proceedings of the 44th IEEE Conference on Decision and Control, and the European Control Conference, CDC-ECC 2005, Vol. 2005, Seville, Spain, pp. 6323-6328.

Holloway, L. E. e Chand, S. (1996). Distributed fault monitoring in manufacturing systems using concurrent discrete-event observations, Integrated ComputerAided Engineering 3(4): 244-254.

Hopccroft, J. E., Motwani, R. e Ullman, J. D. (2007). Introduction to automata theory, languages, and computation, 3rd edn, Addison Wesley, Boston. 
Jiang, S., Huang, Z., Chandra, V. e Kumar, R. (2001). A polynomial algorithm for testing diagnosability of discrete-event systems, IEEE Transactions on Automatic Control 46(8): 1318-1321.

Jiang, S., Kumar, R. e Garcia, H. E. (2003). Diagnosis of repeated/intermittent failures in discrete event systems, IEEE Transactions on Robotics and Automation 19(2): 310-323.

Kilic, E. (2008). Diagnosability of fuzzy discrete event systems, Information Sciences 178(3): 858-870.

Lafortune, S., Teneketzis, D., Sampath, M., Sengupta, R. e Sinnamohideen, K. (2001). Failure diagnosis of dynamic systems: an approach based on discrete event systems, Proceedings of the American Control Conference, Arlington, VA, pp. 2058-2071.

Lefebvre, D. e Delherm, C. (2007). Diagnosis of des with petri net models, IEEE Transactions on Automation Science and Engineering 4(1): 114-118.

Li, Z. H., Li, P. e Li, Y. M. (2006). The relationships among several types of fuzzy automata, Information Sciences 176(15): 2208-2226.

Lima, S. T. S., Basilio, J. C., Lafortune, S. e Moreira, M. V. (2010). Diagnose centralizada de falhas de sistemas a eventos discretos robusta à perda permanente de sensores, XVIII Congresso Brasileiro de Automática, Bonito, MS. (submetido para apresentação).

Lin, F. (1994). Diagnosability of discrete event systems and its applications, Discrete Event Dynamic Systems: Theory and Applications 4: 197-212.

Lin, F. e Wonham, W. M. (1990). Supervisory control and coordination of discrete-event systems with partial observation, IEEE Transactions on Automatic Control 35: 1330-1337.

Lin, F. e Ying, H. (2002). Modeling and control of fuzzy discrete event systems, IEEE Transactions On Systems Man And Cybernetics Part B-Cybernetics 32(4): PII S 1083-4419(02)03116-3.

Liu, F., Qiu, D., Xing, H. e Fan, Z. (2008). Decentralized diagnosis of stochastic discrete event systems, IEEE Transactions on Automatic Control 53(2): 535-546.

Lunze, J. e Schroder, J. (2001). State observation and diagnosis of discrete-event systems described by stochastic automata, Discrete Event Dynamic Systems: Theory And Applications 11(4): 319-369.
Manyari-Rivera, M., Basilio, J. C. e Bhaya, A. (2007). Integrated fault diagnosis based on Petri net models, Proceedings of the 16th IEEE International Conference on Control Applications, Singapore, pp. 958-963.

Moreira, M. V., Jesus, T. C. e Basilio, J. C. (2010). Polynomial time verification of decentralized diagnosability of discrete event systems, Proc. of the American Control Conference, Baltimore, Maryland, USA. Aceito para apresentação.

Murata, T. (1989). Petri nets - properties, analysis and applications, Proceedings of the IEEE 77(4): 541-580.

Paoli, A. e Lafortune, S. (2005). Safe diagnosability for faulttolerant supervision of discrete-event systems, Automatica 41(8): 1335-1347.

Paoli, A., Sartini, M. e Lafortune, S. (2008). A fault tolerant architecture for supervisory control of discrete event systems, Proceedings of the 17th IFAC World Congress, Vol. 17, South Korea.

Peterson, J. (1981). Petri net theory and the modeling of systems, Prentice Hall, Englewood Cliffs, NJ.

Qiu, W. e Kumar, R. (2006). Decentralized failure diagnosis of discrete event systems, IEEE Transactions on Systems, Man and Cybernetics, Part A 36(2): 384-395.

Qiu, W., Wen, Q. e Kumar, R. (2009). Decentralized diagnosis of event-driven systems for safely reacting to failures, IEEE Transactions on Automation Science and Engineering 6(2): 362-366.

Ramadge, P. J. e Wonham, W. M. (1989). The control of discrete-event systems, Proceedings of the IEEE 77: 81-98.

Ramirez-Trevino, A., Ruiz-Beltran, E., Rivera-Rangel, I. e Lopez-Mellado, E. (2004). Diagnosability of discrete event systems. A Petri net based approach, Proceedings of IEEE International Conference on Robotics and Automation, Vol. 2004, New Orleans, LA, pp. 541-546.

Ru, Y. e Hadjicostis, C. N. (2009). Fault diagnosis in discrete event systems modeled by partially observed petri nets, Discrete Event Dynamic Systems: Theory And Applications 19(4): 551-575.

Sampath, M. (2001). A hybrid aproach to failure diagnosis of industrial systems, Proc. of the American Control Conference, Arlington, VA, pp. 2077-2082.

Sampath, M., Lafortune, S., e Teneketzis, D. (1998). Active diagnosis of discrete-event systems, IEEE Trans. on Automatic Control 43: 908-929. 
Sampath, M., Sengupta, R., Lafortune, S., Sinnamohideen, K. e Teneketzis, D. (1995). Diagnosability of discrete-event systems, IEEE Trans. on Automatic Control 40: $1555-1575$.

Sampath, M., Sengupta, R., Lafortune, S., Sinnamohideen, K. e Teneketzis, D. (1996). Failure diagnosis using discrete event models, IEEE Trans. on Control Systems Technology 4: 105-124.

Simsek, H. T., Sengupta, R. e Eskafi, F. (1999). Fault diagnosis for intra-platoon communications, Proc. of the 38th IEEE Conference on Decision and Control, Piscataway, NJ, USA, pp. 3520-3525.

Thorsley, D. e Teneketzis, D. (2005). Diagnosability of stochastic discrete-event systems, IEEE Trans. on Automatic Control 50: 476-492.

Tripakis, S. (2002). Fault diagnosis for timed automata, in Springe-Verlang (ed.), Lecture notes in computer sciences, In Formal Techniques in Real Time and Fault Tolerant Systems (FTRTFT), Vol. 2469.

Ushio, T., Onishi, I. e Okuda, K. (1998). Fault detection based on Petri net models with faulty behaviors, Procee- dings of the IEEE International Conference on Systems, Man and Cybernetics, Vol. 1, San Diego, pp. 113-118.

Wang, Y., Yoo, T. S. e Lafortune, S. (2007). Diagnosis of discrete event systems using decentralized architectures, Discrete Event Dynamic Systems: Theory And Applications 17(2): 233-263.

Yoo, T.-S. e Lafortune, S. (2002). Polynomial-time verification of diagnosability of partially observed discreteevent systems, IEEE Transactions on Automatic Control 47(9): 1491-1495.

Zad, S. H., Kwong, R. e Wonham, W. (2005). Fault diagnosis in discrete-event systems: incorporating timing information, Automatic Control, IEEE Transactions on 50(7): 1010-1015.

Zad, S., Kwong, R. e Wonham, W. (1999). Fault diagnosis in timed discrete-event systems, Proceedings of the IEEE Conference on Decision and Control, Vol. 2, Phoenix, Arizona,USA, pp. 1756-1761. 